Elsevier required licence: (C) $<2016>$. This manuscript version is made available under the CC-BY-NC-ND 4.0 license http://creativecommons.org/licenses/by-nc-nd/4.0/ 
1

Energy Policy, V olume 96, September 2016, Pages587- 596. Final editorial changeswasnot reflected in thisdraft.

\title{
Gas and LNG trading hubs, hub indexation and destination flexibility in
}

\author{
East Asia
}

SHI Xunpeng, Energy Studies Institute, National University of Singapore.

Tel: +65 6516 5360; Email: shi@nus.edu.sg

Hari Malamakkavu Padinjare Variam, Energy Studies Institute, National University of Singapore.

Tel: +65 65167083; Email: esihar@nus.edu.sg

\begin{abstract}
In the East Asian gas markets, issues like gas trading hubs, hub indexed pricing, and destination flexibility are being debated. This paper examines the impact of a change in East Asia's pricing benchmark and contract flexibility on the regional and global gas markets. The paper uses the Nexant World Gas Model, a linear program with global cost minimization as the objective. To our knowledge, this study on hub competition, price benchmark change and contract flexibility improvement in East Asia will be a first in the literature and have real policy relevance. The results show that both price benchmark change and contract flexibility improvements will create an overall positive effect on the world and East Asia importers, but the impacts are different among exporters and importers. However, there is no evidence of competition among different benchmark hubs and destination restrictions cause the "Asia Premium". It implies that removal of destination clauses has higher priority than the change to hub indexation for Japan, Korea and Chinese Taipei, but both should be treated equally in China. The study also suggests that East Asian importers should cooperate among themselves and with exporters to facilitate the hub creation and contract changes in East Asia.
\end{abstract}

Key Words:

Gas; Trading Hub; Hub indexation; Destination Clause; China; Japan 


\section{Introduction}

East Asia is gearing to change its dominant oil indexed long term contracts to more flexible hub (spot) indexed contracts for its LNG and gas imports. Most LNG to East Asia was traded under oil indexed contracts despite LNG to East Asian region coming from various countries of origin (Aguilera et al., 2014). The share of oil indexed gas (both LNG and pipeline) in East Asia was 88\%, much higher than the global average of 65\% (IGU, 2015). However, the oil indexed pricing mechanisms face many criticisms such as substantial gaps in prices between North America, Europe, and Asia due to the difference in pricing mechanisms when oil prices were high. ${ }^{1}$ It is thus of East Asia's interest to create its own regional gas trading hubs that can generate more transparent price index reflecting the region's own supply and demand fundamentals for its gas trade, move away from oil indexation to the hub indexation, and improve contact flexibility.

Understanding the impact of hub creation, hub indexation and contract flexibility (hereafter contract changes) in East Asian gas on regional gas market is a current need of national policy formulation in East Asia. Natural gas occupies widely differing positions in East Asia and thus the impact would be diversified and complicated. In China and India, natural gas is a minor fuel accounting for $6 \%$ and $9 \%$ of the primary energy supply respectively (BP, 2015b), but it is expected to grow fast in the next two decades (IEA, 2015). In 2014, the share of gas in total primary energy supply was about $20 \%$ in Japan and about $15 \%$ in South Korea (BP, 2015b), but growth prospects are uncertain in the short term and muted in the long term (IGU, 2015). Moreover, these changes need the

\footnotetext{
${ }^{1}$ North American prices reflect gas supply-demand balances; European prices are linked both to oil prices and hub prices; while Asian prices are linked to crude oil prices. 
cooperation of exporters and thus an understanding of impact will be necessary to facilitate the hub creation and contract changes.

Given the significance of East Asia in the world's LNG market, examination of the impact of East Asia's contract changes is also important for the regional and global gas markets. The Asian natural gas market is the fastest growing gas market worldwide. The share of East Asia in the global gas market will increase from $18.8 \%$ in 2012 to $26.3 \%$ in 2035 (BP, 2015a). Due to its geographic reach and flexibility of supply, LNG is expected to continue play a leading role in the East Asia's gas market. IEA (2013) predicts that Asia may absorb $80 \%$ of the incremental LNG imports over the medium term, among which, China alone will absorb $30 \%$.

This paper will examine the potential impact of East Asian's efforts in creating hubs and changing contract terms, including transition to hub indexation and removal of destination clauses in the LNG contracts. Potential competition in the East Asian between a Shanghai benchmark price and a Tokyo benchmark price is also examined. Questions to be answered are: What are the impacts of adoption of an East Asian price benchmark for gas and LNG imports into East Asia ${ }^{2}$ ? What could be the difference of the impact between a Shanghai price benchmark and a Tokyo price benchmark? What would be the impact of removing the destination clauses in LNG contracts?

This paper fits into a relatively large research area that considers the impact of certain dynamics in the natural gas sector on gas markets. Although many similar work has been done on how shale gas impacts natural gas markets (Wakamatsu and Aruga, 2013), what would be the impacts of additional infrastructure or integrated gas market (Chang and $\mathrm{Li}$,

\footnotetext{
${ }^{2}$ China, Japan, South Korea and Chinese Taipei 
2011), how the US export of LNG will have impact on the US domestic market (EIA, 2012) and global gas markets (Arora and Cai, 2014; Maxwell and Zhu, 2011; Moryadee et al., 2014), only a few studies in the literature discuss issues of natural gas and LNG contract issues such as change of the European long term contracts (Talus, 2011), and cost minimization of contracts (Khalilpour, 2011).

The discussions on East Asia's gas trading hubs, hub indexation and destination flexibility are limited to a few recent studies (IEA, 2013, 2014a; Tong et al., 2014) due to the nascent changes in East Asia's gas market. Only a few recent studies (Rogers and Stern, 2014; Stern, 2014) have paid attention to the gas trading hubs, hub indexation pricing mechanism and destination clauses in East Asia (IEA, 2013, 2014a; Rogers and Stern, 2014; Stern, 2014; Tong et al., 2014). Shi and Variam (2015) is the only study that quantified the impact of adoption of the Shanghai hub price in China's gas imports on China-Australia LNG trade. However, no existing study has examined the impact of those contract changes in price benchmarks and removal of destination clauses on the gas markets at East Asian regional level.

To the best of our knowledge, this is the first modelling analysis to quantify the impact of East Asia's changes in gas pricing benchmark, removal of destination clauses and creation of gas trading hubs. This paper not only fills the gaps in the literature, but also have direct relevant policy implications as the East Asian gas importers need this information to make decisions in their process of liberalizing gas markets, building gas trading hubs and changing gas import contracts.

The rest of the paper is organized as follows. Section 2 reviews the East Asian gas pricing transition and hub initiatives, highlighting the competition hypothesis among 
three countries: China, Japan and Singapore. Section 3 explains the model and the scenarios. Section 4 analyses the modeling results including discussions. The last section concludes the paper with policy implications.

\section{Policy initiatives and debates on hub pricing and contract flexibility in East Asia}

Trade of natural gas, in particular, LNG, is facing challenge on pricing benchmark. The oil indexed pricing mechanisms for LNG in Asia markets, although successful until 1990s, currently faces few major criticisms. Firstly, oil is no long a major competitor to gas in the end use market. Indexation to oil will allow supply/demand factors in oil markets, and not in the gas market, to set the wholesale price of natural gas and thus is no longer appropriate (IEA, 2013). Secondly, as the European case shows, the competition between gas and coal in power generation has become more important (IEA, 2012) ${ }^{3}$. Thirdly, the oil indexation also results in relatively higher prices than hub-indexed gas prices in the USA and Europe during a period of high oil prices. The "Asia premium" leads to concerns that Asia's economies will lose competitiveness (IEA, 2013). Lastly, the gas pricing that is realized through regional gas to gas competition in Europe and North America will not reflect Asia's market fundamentals since gas market is more regional than global (Stern, 2012).

These criticisms and the development in the European continental gas markets has fueled the debate on how to create gas trading hubs in East and Aisa and how to price natural gas according to the region's supply and demand fundamentals (IEA, 2013). An Asian

\footnotetext{
${ }^{3}$ Reduced coal demand in US has resulted in lower US coal prices exported to Europe, thus directly affecting gas demand for power generation. 
hub based price is also needed, because practically, without a local competitive spot market for natural gas, there is little incentive to change current oil indexation practices, especially from the suppliers' perspective.

\subsection{Gas hubs and regional competition for benchmark price setting}

Many East Asian importers have started to create its own regional gas pricing benchmark through the establishment of gas trading hubs. Currently, Singapore, Japan and China are leading the hub initiatives in East Asia. While it is generally believed that Asian hubs can bring benefits such as enhanced flexibility and transparency of the gas markets (IEA, 2014a), such benefits could be diversified among countries. National policymakers need to understand the impact of such a change of price benchmark to make their decisions.

So far Singapore has led the way. Given its advantages of liberalized electricity and gas markets, good reputation of legal, fiscal and financial regimes, and experience in developing an oil trading hub, IEA (2013) argued that Singapore could create the first benchmark gas trading hub in Asia. In June 2015, Singapore Exchange (SGX) launched an Asian spot LNG index, that is, FOB Singapore SGX LNG Index Group ("FOB Singapore SLInG") (Energy Market Company, 2015).

To create a competitive market that supports the hub, China has also unveiled its gas market reform strategy, including removal of administrative monopoly, liberalization of prices, and fair playground for both state and private companies, and unbundling. China has also made concrete progress and plans to create a China spot gas price. A recent survey of the market reform and liberalization efforts can be found in Shi and Variam (2015). China opened its gas trading platform in Shanghai to promote a market-oriented 
pricing mechanism on 1 July 2015 (Shanghai Daily, 2015), a concrete step toward the Chinese 'Henry Hub' (China Securities Newspaper, 2015).

Japan is in the process of developing its Tokyo LNG hub and LNG benchmark prices, as well as gas and electricity market liberalization. The first Japan OTC Exchange (JOE)facilitated LNG non-deliverable forward deal was made on July 31, 2015 (Tsukimori, 2015). Full retail market deregulation in the Japanese electricity and gas sectors is scheduled for April 2016 and early 2017 respectively. Other gas and electricity business law reforms will continue through 2022 (The Japan Times, 2015).

There is a concern that the hub initiatives among the three leading countries are mutually exclusive in offering a benchmark price for the region (IEA, 2013). The competition among East Asian countries for regional gas trading hubs and pricing benchmarks is therefore emerging as important policy issues and therefore need to be addressed. If there is no significant difference among various benchmark prices, the creation of gas trading hubs could be compatible while not exclusive.

\subsection{Destination flexibility}

Relaxation of destination restrictions has also been under debate in East Asia. Natural gas, in particular LNG, are often traded under rigid long term contacts with destination restrictions. These clauses are introduced for reasons such as securing supply and investment (Glachant and Hallack, 2009; Thomas et al., 2000). However, these restrictions will cause inefficiency in the gas market. A study of real option valuation of free destinations in long-term LNG supplies argues that free destinations are highly likely to improve between $6 \%$ and $43 \%$ of the value of long-term LNG supplies (Yepes 
Rodríguez, 2008). Further studies are still needed in order to convince exporters to accept the changes.

The current market conditions also favor free destinations. The LNG business practice is changing rapidly with increasing medium-term or short-term (spot market) contracts and a shift from DES (Delivered Ex Ship) to FOB (freight-on-board or free-on-board) for a number of reasons, including more competition from gas market liberalization (Khalilpour, 2011). The emergence of competitive regulations also prevents the contractors from having any destination clauses in their sales and purchase agreements (Cogan, 2005). The EU decision that destination restrictions are not permissible from a competition policy perspective; and G-7 nations and APEC agreed to relax such restrictions (Rowley, 2014).

\section{Method: model and scenarios}

As a tool for studying the global impact of East Asia's pricing transition, this paper uses the Nexant World Gas Model (WGM) ${ }^{4}$ (Nexant, 2016) to study the effects of hubs, adoption of spot market prices as trading benchmark, and the improvement of flexibility in contracts in East Asia. A baseline scenario is developed as a reference case to study how the international gas market might evolve to 2035. In this scenario, all the contracts have 'take or pay' (TOP) and destination clauses built in and long term contracts are indexed to oil prices. This is the reference case with which we compare the results from

\footnotetext{
${ }^{4}$ Nexant World Gas Model is a current information model. In simulations, the model combines supply, demand and infrastructure information to determine a market price that allows production, exports and imports to balance consumption in each year. Market clearance is assumed to happen at a price where the supply at the marginal cost of procuring gas is sufficient to meet demand.
} 
our alternative (policy) scenarios. The difference between scenarios is analyzed to draw recommendations.

\subsection{The Asian Gas Trade Model}

The WGM model is formulated as a linear program with global cost minimization as the objective. The WGM covers every country in the world which consumes or produces natural gas. Countries are modelled as nodes in WGM. The model captures flows at the node level by pipeline and LNG and contracted and un-contracted flows are separately identified.

While most countries are modeled as single node, larger countries such as Australia, Canada, China, Indonesia, Malaysia, Russia and USA, are further divided into several nodes. For example, Russia is divided into 7 nodes, each having their own supply, demand and contract characteristics. Nodes are balanced on a quarterly basis to account for seasonal demand variations, supply swing, flexibility of delivery infrastructure and storage capacities. The model is optimized at node level but the results are aggregated to country and even regional blocks to simplify the presentation.

The model assumes that gas market will be adequately supplied in the forecast period which is accounted for by provisioning production capacity in key producer countries at low to medium cost in line with IEA WEO projections (IEA, 2015).The model minimizes cost of production and transportation to meet projected demand, subject to infrastructure constraints. Flows within nodes are constrained according to the available infrastructure and within the bounds of long term contracts where appropriate. Long term contracts can be prolonged or allowed to expire at the end of existing terms. If contracts are allowed to expire, this would create more opportunities for spot trade to occur. 
If the export and import nodes are both specified, the model will deliver at least the takeor-pay (TOP) level from the export node to the import node. Volumes above the TOP level can be delivered to the import node, diverted to another location or even shut in (not produced). The model decides between options on economic grounds. Spot trade (uncontracted flow) can take place with respect to any available liquefaction and regasification capacity over and above that needed for contractual obligation. Spot price is determined as a function of marginal cost of production, supply demand balance and the cost of alternate fuels.

The classification of other regions is according to the International Gas Union's classification. Key Asian gas players, namely China, Japan, South Korea, Chinese Taipei, Asia Pacific Exporters and the rest of Asia were modelled separately (for gas infrastructure, demand and supply) as we focus on impact on the consumers and producers in the East Asian region. Japan, Korea, and Chinese Taipei (JKT) are also collectively named as "other East Asian importers" when compared with China. For ease of analysis and relevance for our study, we have classified regions as in Table 1.

\section{Table 1 Definition of regions}




\subsection{Model assumptions and inputs}

The exogenously specified demand ${ }^{5}$ forecasts for each node are estimated based on economic growth, energy intensity and population growth at sectoral level. Supply data is included as a cost curve for each of the natural gas fields for the producing country.

The model also takes into consideration the infrastructure needed to support international trade including production fields and basins, pipelines, LNG liquefaction and regasification terminals and storage facilities, together with their associated costs. ${ }^{6}$ The model includes all known sales contracts, and active and planned infrastructure (pipelines and LNG liquefaction and regasification terminals). Contracts data includes source and destination, Annual Contract Quantity (ACQ), start and end dates, price formula. In addition, essential variables such as seasonal demand variations, supply swing and storage capacities (working volume and deliverability) were also included in the model as inputs.

Oil product prices are included in the model as they are used to derive gas prices under long term gas contracts (oil-indexed contracts) into Europe and $\mathrm{Asia}^{7}$. The historical data are available from 2006 to 2013 and outlook period is up to 2035 .

For more details on the specifications of the assumptions and inputs, please refer to the Appendix.

\footnotetext{
${ }^{5}$ The forecasted natural gas demand is different from realized consumption. Demand is an input to the model and Consumption is an output of the model. Consumption is almost always is equal to demand. But Consumption can be less than demand (Demand Side Reduction - DSR) due to i) supply bottlenecks and ii) increase in gas prices above price of alternate fuels, which leads to fuel switching.

${ }^{6}$ This model database includes all known sales contracts, active and planned infrastructure (pipelines and LNG liquefaction and regasification terminals). Contracts data includes source and destination of contracts, contract ACQ, contract start and end dates, price formula are the key parameters for adjustment. The infrastructure information includes information on location, start and end dates of operation, source and destination, pipeline capacity, start and end dates of pipelines and transportation tariffs.

${ }^{7}$ Specifically, the Japan Crude Cocktail (JCC) is often used as a benchmark for LNG contracts particularly in the Far East and HFO (High Sulphur Fuel Oil) price is the benchmark for pricing gas contracts in Europe.
} 


\subsection{The baseline scenario}

This section presents a brief overview of the results in the baseline scenario (in terms of consumption, production, LNG trade, and spot prices) to which the simulations are compared. Further details of the baseline scenarios can be found at Andrews-Speed et al. (2015).

In the baseline scenario, a cumulative average growth rate (CAGR) of global natural gas production and consumption at $1.49 \%$ during the outlook period (2015-35) was found. Global natural gas production and consumption increases from $3561 \mathrm{bcm}$ in 2015 to 4790 bcm in 2035 (Figure 1), which is broadly consistent with the International Energy Agency's forecasts (IEA, 2014b). The largest growth in gas consumption comes from Asia, particularly from China and India. Gas consumption also grows rapidly in the Latin America, Africa and Middle East. Gas consumption grows more moderately in Former Soviet Union (FSU) and slowly in Europe.

Figure 1 Gas consumption forecasts in bcm by region (2006-2035)

\section{Source: Model's projections}

North American production is expected to grow rapidly, driven by the unconventional gas boom in the USA and (to a lesser extent) in Canada. Gas production increases significantly in Asia, driven by rising domestic demand for gas as well as increased Australian production. Increases in African production after 2020 are also export-driven, whereas production growth in the Middle East, Latin America and FSU is mostly driven by rising domestic demand for gas. European production decreases due to declining 
conventional gas production, though the emergence of shale gas slows down the rate of decline after 2025 (Figure 2).

Figure 2 Gas production forecasts in bcm by region (2015-2035)

Source: Model's projections

Global LNG trade flows increase from $330 \mathrm{bcm}$ in 2015 to $497 \mathrm{bcm}$ in 2035, dominated by LNG import in Asia, mainly East Asia. Asia Pacific exporters dominate LNG supply in the East Asia region (China, Japan, Korea and Chinese Taipei) supplying over $56 \%$ of the East Asian LNG demand till 2035. Middle East supplies over 17\% of the regional LNG demand over the outlook period. North America and Africa expand LNG supply share in the region from $0 \%$ in 2015 to over $27 \%$ by 2035 . LNG flows into East Asia are expected to grow rapidly in line with economic growth and then remain stable as pipeline flows from FSU and Russia increase. The marginal decrease in LNG flows to East Asia post 2028 is due to reduction in LNG flows from Africa to China as pipeline gas is more competitive at the margin when compared to LNG from East Africa. Subsequent decrease is also due to decrease in LNG flows from Russia to China as pipeline flows increase.

Figure 3 LNG Flows to East Asia, 2015-2035

Source: Model's projections

Spot prices in Asia generally show an overall increasing trend, with decline (in line with decline in oil prices) till 2019 and then increasing thereafter (Figure 4). Increased demand 
from China results in a fast increasing spot price trajectory for China, where the spot price is highest among the nodes $(\$ 12.5 / \mathrm{mmbtu})$, closely followed by other Asian prices. This would imply that Asian prices are expected to be higher in the markets. European spot prices also move upward due to increased spot LNG exports and decreased contracted pipeline exports from Russia. Prices in East Asia (Japan and Korea) marginally declines in 2028-2030 when compared to Chinese prices. The marginal decline is on account of expiration of high price oil indexed contracts in Japan and Korea.

Figure 4 Gas Prices, Baseline (\$/mmbtu) (2015 - 2035)

Source: Model's projections

\subsection{Scenario setting}

A total of six alternative (policy) scenarios are set up and simulated.

In Scenario 1-'Shanghai Hub' (S1), China's Shanghai hub (spot) prices become the price benchmark for both pipeline gas and LNG trade into East Asia. The Shanghai hub price is formed within the range of the marginal cost of supply of gas (shadow price) in Shanghai and gas-on-gas competition with LNG prices in the region. ${ }^{8}$ All active pipeline and LNG contracts post 2025 in those East Asian importers (China, Japan, South Korea and Chinese Taipei) are indexed to Shanghai hub price, a pricing mechanism that is similar to how natural gas is currently priced in the United States and the United

\footnotetext{
${ }^{8}$ The competing fuel prices used in calculation were: average China Piped contract price, Japan spot price, and average LNG contract price from Australia.
} 
Kingdom. This allows for simulation of the effect of a hub price in the region. The year used for start of hub prices in the scenario is selected based on the minimum 5-10 year time reported for adoption of a regional benchmark in Asia (Rogers, 2015). This scenario has been individually analyzed in detail in Shi and Variam (2015) from the perspective of China market liberalization and its impact on Australian LNG exports.

In Scenario 2-'Tokyo Hub' (S2), Japan's Tokyo hub (spot) prices replace Shanghai hub prices as the price benchmark for both pipeline gas and LNG trading by the East Asian importers, while everything else is identical with Scenario S1. This allows for a study of the effect of different benchmark hubs in East Asia.

In Scenario 3 and 4, we remove the destination clauses from all LNG contracts ${ }^{9}$ in the East Asian region. In scenario 3-'Hub no DS' (S3), we assume that the regional market is indexed to Shanghai hub price with gas-on-gas competition of piped and LNG prevailing in the region. While scenario 4-'Oil no DS' (S4) retains the pricing status quo of a mix of predominantly oil indexed contracts in the Baseline scenario. The scenario 3 simulates a fully liberalized regional gas market while scenario 4 follows what most market observers consider the likely real world outcome, which is the removal of destination clauses as the first step in the way forward for a more competitive market.

We sub divide scenarios into $3 a, 3 b$ and $4 a, 4 b$. Scenarios $3 a$ and $4 a$ see the start date of destination free contracts at 2020 while the scenario $3 b$ and $4 b$ see the start date in $2025 .{ }^{10}$ The different starting points used in simulations is based on the concept that hub indexation needs hub creation and domestic market liberalization which may take a decade to complete. In contrast, removal of destination clauses is a pure contract arrangement and does not rely on other factors that needs long preparation time.

\footnotetext{
${ }^{9}$ Pipelines by its node to node connections (e.g.: Russia Far East to China) do not allow for destination flexibility as is the case with LNG shipments to different ports. Hence pipeline contracts are not changed in both the destination flexibility scenarios.

${ }^{10}$ The 5 and 10 year period is conservative with consideration of outlook of oversupply in LNG markets and the continuing emerging of portfolio suppliers who do not mandate destination restriction anymore.
} 
However, scenario $3 b$ and $4 b$ are simulated to be comparable with Scenario 1 and the
baseline scenario. A summary of the scenario setting is presented in Table 2.

Table 2 Summary of the Scenario Setting

\section{Analysis}

\subsection{Impact of alternative price benchmarks}

The emergence of regional hub-based prices will have an impact on trade and prices of natural gas. When we index all the East Asian regional contracts to Shanghai hub price (S1), the spot prices in China and Japan decline by up to $-\$ 0.8 / \mathrm{mmbtu}$ when compared to the baseline scenario (Figure 5). For the other regions (UK and US), spot prices are also lower. The global decrease in spot prices is due to i) the gas on gas competition leading to lower competing prices; and ii) supply is more abundant with increased production from Australia, North America and Africa resulting in a less tight buyers' market.

Figure 5: Spot Price: Shanghai Hub (S1) vs Base

Source: Model's projections

The relative competitiveness of different regions in supplying gas to Japan, Korea and Chinese Taipei in the event of a spot indexed regional market is not largely affected (Figure 6). This is because: i) Asian supply is tied to long term contracts with TOP clauses, making the majority of supply impervious to competitive pressures; ii) the regional demand is also increasing with limited production options in Japan, Korea and 
Chinese Taipei, hence the total contracted and uncontracted flow to East Asia increases in line with increase in demand. The marginal reorganization of trade flows can be explained by the cost competitiveness of piped gas in China which displaces LNG at the margin in China while Japan, Korea and Chinese Taipei is able to take advantage of cheaper Australian gas ${ }^{11}$ and Middle East gas is able to maintain its competitive advantage, while African and US exporters lose out in market share.

\section{Figure 6 LNG Flows to Japan, Korea and Taiwan (Shanghai Hub (S1) vs Base case) Source: Model's projections}

Pipeline exports to China is seen more competitive due to the lower delivered price at border in a hub indexed scenario. This results in an increase in exports from Central Asia. LNG flows from Africa, South Asia, Russia and Middle East get displaced by domestic production and piped gas in China (Figure 7). LNG exports to China is seen as less competitive due to higher spot prices (in gas producing provinces) incentivizing domestic production and the cost competitiveness of piped gas from central Asia. The higher domestic production, reduced LNG imports and higher pipeline imports increases China's supply security.

Figure 7 LNG and pipeline Flows to China in bcm (Shanghai Hub (S1) Vs Base scenario) Source: Model's projections

\footnotetext{
${ }^{11}$ Australian shadow prices decreases the most by an average of $\$ 0.50 / \mathrm{mmbtu}$ when compared to base case. 17
} 
The combination of reduced spot prices and only marginal reorganization of trade flows with constant consumption, make the region better off in terms of cost of procurement. The combination of displaced natural gas exports by pipeline gas and domestic production in China makes some of the higher cost exporters (USA, Africa) potentially worse off in a hub indexed East Asian region.

In the Tokyo Hub scenario (S2), change in regional indexation to Tokyo hub price, when compared with the Shanghai Hub scenario have no significant difference on both regional and the world production, consumption and trade flow patterns.

However, the regional spot prices in the two hub indexed scenarios (scenario S1 vs S2) are different. In the Shanghai Hub scenario, the spot prices in China are higher by up to $\$ 0.4 / \mathrm{mmbtu}$ than in the Tokyo hub scenario. The decrease in spot prices in the Tokyo Hub scenario is due to i) the Japanese market (which is the regional benchmark) sees true LNG gas-on-gas competition in an oversupplied LNG market, which results in lower spot price. In contrast, the Chinese market has a mix of piped gas, LNG and higher cost domestic production supplying the market ii) the Chinese gas market balances the consumption with piped gas and higher domestic production, resulting in slightly higher spot Chinese price. The competing price differential is also on account of lower average freight costs to Japan from Australia.

Figure 8: Spot price: Shanghai hub (S1) vs Tokyo hub (S2) Source: Model's projections 


\subsection{Impact of removed destination clauses}

In the scenario 3 (Hub - No DS) and 4 (Oil - No DS) we are simulating the case of an East Asian market where destination clauses are removed and importers are free to procure cargo from any of the available sellers and direct delivery to any port of his choice.

In 'Hub - No DS' scenario (S3), the consumption patterns for all countries remain the same when compared to the baseline case. Spot prices in the region, except for China, are slightly reduced by the no destination clauses in all the LNG contracts. The NBP prices and the Japanese LNG price decrease up to US\$0.6/mmbtu during the period. This is due to the increased supply to East Asia coming from the displaced demand owing to increased Chinese production. The reduced market tightness in these regional markets is the reason for fall in spot prices (Figure 9).

Figure 9: Spot price: Hub - No DS (3a) vs Base Source: Model's projections

Chinese spot prices increase following the transition period, before slowly declining when compared to the baseline. The initial increase of spot price in China is due to the modelling methods.

This model gives priority to resource deficit importers in allocating of lower price LNG resources. This is clearly demonstrated in the simulation run where supply constrained importers such as Japan, Korean and Chinese Taipei see priority of LNG supply over China which can meet its demand through developing its domestic resources and piped gas options in the long term. Consumer countries with significant production resources 
thus have incentive to develop the marginally higher cost production in such scenarios, as seen from increased production in China. China with its domestic gas resources can better balance its demand with increased production in a supply deregulated (and a more competitive) market (Figure 10). This production increase is incentivized by higher hub indexed gas prices in gas producing regions in China. Thus, China is able to increase its production by $251 \mathrm{bcm}(+8.3 \%)$ in the period $2020-35$, from higher cost unconventional fields resulting in an average shadow price increase of $\$ 0.90$.

China's increased domestic production leads to reduced market tightness resulting in long term decrease in spot prices.

Figure 10 Production: 'Hub-No DS' (3a) vs Base

Source: Model's projections

LNG imports to China decline during the same period and pipeline imports to China (mostly from Central Asia and Russia) increase, thus balancing out the decline in LNG (Figure 11). Total LNG imports decrease by $38 \%$ and total pipeline imports increase by 6\%. LNG imports from Asia Pacific exporters to China are thus displaced by increased domestic production and pipeline gas. Cost competitiveness of piped gas from Central Asia is on account of the lower transportation tariff to supply South China when compared to LNG. The increase in African LNG exports is seen as the difference in Shanghai Hub scenario (S1) vs Shanghai Hub No-DS (S3) scenario. This would imply that African LNG to China is potentially more cost competitive at the margin, than Asian Pacific LNG to China. The pipeline flows to China show two peaks, the first peak in 2021 is on account of Russian pipeline flows and the second one in 2028 is on account of 
pipeline flows from FSU. The differential pipeline flows show an inverted "U" shape where initial increased flows compensate for loss of LNG exports and then flows decline as domestic production is ramped up.

Figure 11 LNG and pipeline flows to China: Hub No DS (3a) vs Base Source: Model's projections

Some of the displaced LNG from Asia Pacific exporters in China flow to Japan, Korea and Chinese Taipei, displacing LNG from North America and Africa (Figure 12). Therefore, Japan, Korea and Chinese Taipei markets see increased LNG imports from Asia Pacific while reduced LNG exports are seen elsewhere.

Figure 12 LNG Exports to Japan, Korea and Chinese Taipei (S3a vs Base) in bcm Source: Model's projections

In Oil - No DS scenario (S4), changes in total production, consumption, LNG trade flows and pipe line trade flows are broadly in line with the results in Hub - No DS (S3) scenario to indicate that impact of relaxation of destination clauses outweighs any change in pricing benchmark ${ }^{12}$.

Spot prices show similar patterns as Hub - No DS (S3), except for China, where the spot price in the Oil - No DS (S4) scenario is higher on an average by $+\$ 0.3 / \mathrm{mmbtu}$ due to higher price of the oil indexed piped gas in China (Figure 13).

\footnotetext{
${ }^{12}$ However, we note that oil indexed Russian pipeline gas to China loses competitiveness against LNG from Middle East at the margin, resulting in minor re organization of trade flows. 
Figure 13: Spot price: Oil no DS (3a) vs Spot No DS (4a)

Source: Model's projections

Based on the study of results, removing destination restrictions for LNG contracts in the region is generally beneficial for East Asian importers. It is also seen that when destination clauses are removed, the price benchmark will not make much difference.

\subsection{Cost of procurement ${ }^{13}$}

In all the alternative scenarios, total procurement costs for the world is seen to be lower by $2.6 \%$ on average, when compared to the baseline (Table 3 ). Therefore, it could be said that both hub indexation and removal of destination clauses are beneficial as they will bring down the global total procurement cost. The hub prices will direct the gas to those that generate the most benefits. While contract flexibility gives consumers the choice of procuring gas from the lowest cost producers and delivering it where it is most needed, the downside could be the propensity for increased competition for the gas, which may lead to volatility in spot prices.

Table 3: Overall cost of procurement (\% change vs base case) 2015-35 in Billions of USD (2012 price)

Source: Model's projections

Among the four alternative scenarios, the removal of destination clause in 2020 (Scenario 3a and 4a) bring lower procurement cost than those hub indexation scenarios (Scenario 1

\footnotetext{
${ }^{13}$ Total Procurement Cost $=$ Production Cost + Piped gas cost $($ contract $\&$ spot $)+$ LNG gas cost (contract + spot) + Regasification cost. Transportation tariffs are assumed to be included in the gas price as contracts are assumed to be DES priced.
} 
and 2 respectively). Cost reductions are due to LNG and pipeline imports at lower spot prices on average and allocation of lowest cost LNG cargo to the region with same demand. However, a later removal of destination clauses will have much lower benefits (scenario $3 \mathrm{a}$ vs $3 \mathrm{~b}$, scenario $4 \mathrm{a}$ vs $4 \mathrm{~b}$ ). This is to be expected as there will be very few contracts which still have destination clauses after 2025 due to expiration of existing contracts.

The reduction of the procurement cost is more significant in all the four East Asian importers than the world average. The hub indexation leads to uniformly lower procurement costs for all East Asian importers (scenario 1 and 2). The slight difference in procurement costs over scenario 1 and 2 is due to of marginal change in spot prices on account of our assumption of competing fuels and transportation costs to each hubs.

However, the allocation of benefits among the four East Asian importers in the non-DS scenarios are quite diversified. Japan, Korea and Chinese Taipei are able to reduce their procurement costs more in the flexible supply scenarios than China. Once the LNG contract is flexible, those countries can minimize costs through arbitrage and other commercial options in a competitive but well supplied market with lower spot prices. In contrast, China imports more pipeline gas than LNG, and the removal of destination clause is only applied to LNG and thus the effect of hub indexation on the Chinese procurement cost is significant while change of destination clause is not significant. Therefore, further introducing market price to the oil indexed pipeline can bring more benefits for China than other East Asian importers.

Once the destination clauses are removed, the procurement costs in East Asian importers other than China are almost identical with or without utilization of hub indexation (S3a vs 
S4a). This is due to the lack of production capacity of these consumers, and thus their reliance on imported LNG. The number of active LNG supply contracts to East Asia is reduced to 63 by 2030 out of a total of 204 in the beginning of 2020 , effectively making the region predominantly spot from 2030 onwards. This explains the small effect on indexation of prices as most of the transactions are based on spot prices with or without hub indexation. In the case of China, price benchmark does matter even without destination clauses: further changes to hub indexation will double the benefits from removal of destination clause from China. However, in the case of later removal of destination clauses, there will be no difference for all importers between hub indexation and oil indexation (Table 3).

\subsection{Discussion}

East Asia faces significant opportunities in the development its own hubs and spot prices. Firstly, the well functional spot and futures natural gas markets, Henry Hub in the USA, National Balancing Point (NBP) and Title Transfer Facilities (TTF) in Europe, provide a leading example for East Asia. Secondly, some projects in Indonesia, Guinea, Nigeria and Qatar have started to offer HH-Indexed prices for LNG supply to Asia (IEA, 2014a). Thirdly, the US LNG exports, priced based on Henry Hub and without destination restriction, raise the hope that liquidity in the East Asian spot markets will increase and could provide a trigger to open discussions with other suppliers on developing new pricing formulas and removing destination clauses. Lastly, the coming of a buyers' market in the global LNG market makes the changing of pricing mechanism towards competitive prices feasible for East Asia. 
The results of change to hub indexation imply that the world would benefit from low procurement costs and thus cooperation among various stakeholders is possible. The results of change to hub indexation also imply that in a geographically close regional market in equilibrium, the choice of different benchmark hub prices will not make significant differences in trade patterns and regional prices. An IEA study concluded that given the large size of East Asian gas markets, over the long term, East Asia could host a few different markets and associated trading hubs, each of which can capture differences between markets (IEA, 2014a).

The results from the two non-DS scenarios suggest that the price difference, or the "Asia Premium", may not be caused by the destination restrictions. In both Non-DS scenarios, the largest amount of price reduction is in the Japan Spot price, which has a maximum reduction of US\$0.6/Mmbtu (Figure 9). Compared with the average price difference between the Japan LNG and the US and European of US\$9.96 and US\$3.68 respectively in the period 2009-2014 when the price gaps were significant (World Bank, 2016), the magnitude of reduction from free destination is marginal. The literature has also demonstrated that the "premium" claim could be wrong. IEA (2014a) identified that in addition to the oil-indexed pricing in long-term contracts, a few reasons may also lead to the price premium for gas in Asian markets: a low level of demand flexibility; pursuance of energy (supply) security as a priority; and a lack of spot prices that reflect the region's own market fundamentals.

Moreover, the expectation that gas hub initiatives will be reducing the 'Asian Premium' (Tong et al., 2014) is unlikely to be met because the hub prices could demonstrate that the Asia's market fundamentals will generate a higher gas prices than that in USA and 
Europe. Such a claim could not be tested without a regional competitive gas markets and market prices.

The relaxation of destination clauses in general will result in more cost savings for East Asian LNG importers than the change of price benchmark. This is due to the nature of contracts being simulated in our model. More than $90 \%$ of the LNG contracts in force expire after 2030, and the consumers buy gas from spot market in all scenarios. Hence, the benefits accrued due to relaxation of price indexation in destination free contracts are not large. For China the difference is significant due to presence of long term, and recently started, pipeline contracts.

\section{Conclusion and policy implications}

This paper examines the potential impact of East Asian's change in pricing benchmarks and improvement in contract flexibility on gas trade. Issues that have been examined including transition from oil indexation to gas indexation; the difference between a Shanghai benchmark price and a Tokyo benchmark price; and the removal of destination clauses in both hub indexed and oil indexed scenarios

The simulations demonstrate that change of gas pricing benchmark and removal of destination clause in the four East Asian importers will have significant benefits for the East Asia and the world. However, the impact on different stakeholders are different. Although some LNG exporters will lose their market in China, their exports could be directed to other East Asian importers. The reduction of total gas procurement costs indicates that the exporters could benefit from the policy changes as well. Furthermore, whether Shanghai or Tokyo hub price is adopted as the benchmark price for the four East Asian gas imports will not make significant difference. This suggests that multiple hubs 26 
initiatives are not mutually exclusive and there is likely to have more than one hub that offers different benchmark prices. This study also finds that the "Asian Premium" is not caused by destination restriction as the price reductions in the non-DS scenarios are marginal. It further demonstrates that the impact of relaxation of destination clause outweighs any change in pricing formula in Japan, Korea and Chinese Taipei. However, for China, the change of indexed benchmark is still significant due to predominance of pipeline exports in the long term.

The paper implies that given the existence of common benefits and a lack of competition among hubs, the East Asian importers, and the exporters, should cooperate with each other to facilitate the East Asian market transition. While removal of destination clauses should be given priority in other East Asian importers due to large benefits and low level of difficulty, hub creation should be give equal consideration in China due to large benefit of switch to hub indexation for pipeline import. Specifically, the following policy suggestions could be generated:

First, the East Asian importers should work together to build trading hubs that generate spot prices. Cooperation is also needed in the removal of destination clause. These policies are in the common interest of all, while presenting little, if not no, conflicting interests. Furthermore, hub supportive efforts, such as liquidity generation and market liberalization, are common challenges for East Asia.

Second, the removal of destination clause should be given higher priority than indexation change for two reasons: one being it does not need domestic market liberalization and thus is easier to be implemented when compared with change price indexation; and two being the change to hub indexation will not add benefits when destination clauses are 
removed in 2020 for Japan, Korea and Chinese Taipei. A transition to hub indexation may take a longer time to achieve because such indexation needs a hub that generates spot prices in a liberalized, or competitive market. Such a liberalized market has not been seen in those East Asian importers and will have to take time and efforts. However, improving the flexibility of gas contracts are easier to be implemented because an importing government should have the sovereignty to ban firms under its jurisdiction to sign contracts with destination clauses, such as in the case of European Union (EU) (Cogan, 2005).

Third, for China, given the significant additional benefits from change of price indexation due to presence of pipeline gas imports, the change price benchmark should be given equal consideration as destination clause removal.

Last, both importers and exporters need to work together as such changes would never materialize without the cooperation between them. Although the alternative policy scenarios will result in loss of competitiveness of LNG to piped gas and China's domestic production, the reduction of global total procurement costs would result in lower productions costs for exporters, thus making them overall beneficiaries of the change. For importers, the switch to hub indexation is not an easy job: they will have to liberalize their domestic gas and electricity markets and restructure their gas industry.

\section{Acknowledgement}

We owe gratitude to Jacqueline Tao for her comments and proofreading of this paper. All errors are authors' own responsibilities. 


\section{Appendix A}

Key assumptions and inputs

\section{References}

Aguilera, R.F., Inchauspe, J., Ripple, R.D., 2014. The Asia Pacific natural gas market: Large enough for all? Energy Policy 65, 1-6.

Andrews-Speed, P., Lixia, Y., Zahur, N.b., Rohatgi, A., M.P., H., Regan, T., Linga, P., 2015. International Outlook for Unconventional Gas and Implications for Global Gas Markets. Energy Studies Institute, National University of Singapore, Singapore.

Arora, V., Cai, Y., 2014. U.S. natural gas exports and their global impacts. Applied Energy 120, 95-103.

BP, 2015a. Energy Outlook $2035 . \quad$ Avaiable at: http://www.bp.com/en/global/corporate/about-bp/energy-economics/energyoutlook.html [Accessed on: 26 Feb 2015].

BP, 2015b. Statistical Review of World Energy 2015. British Petroleum, London.

Chang, Y., Li, Y., 2011. An Integrated Asian Natural Gas Market: Potentials and Policy Implications, in: Kimura, F., Shi, X. (Eds.), Deepen Understanding and Move Forward: Energy Market Integration in East Asia. Economic Research Institute for ASEAN and East Asia, Jakarta, pp. 237-265.

China Securities Newspaper, 2015. Xinhua Newagency is Leading the Efforts to Set up the Shanghai Oil and Gas Trading Center (in Chinese), China Securities Newspaper.

Cogan, J.P., 2005. Contracting practices evolve for new global LNG trade. Oil Gas Journal, 14-17.

EIA, 2012. Effect of increased natural gas exports on domestic energy markets. U.S. Energy Information Administration, Washington, D.C.

Energy Market Company, 2015. About SLInG. Avaiable at: https://www.emcsg.com/sling/aboutsling [Accessed on: 4 Sep 2015].

Glachant, J.-M., Hallack, M., 2009. Take-or-pay contract robustness: A three step story told by the Brazil-Bolivia gas case? Energy Policy 37, 651-657.

IEA, 2012. Gas Pricing and Regulation: China's Challenges and IEA Experience. IEA, Paris.

IEA, 2013. Developing a Natural Gas Trading Hub in Asia: Obstacles and Opportunities. International Energy Agency, Paris.

IEA, 2014a. The Asian Quest for LNG in a Globalizing Market. International Energy Agency, Paris.

IEA, 2014b. World Energy Outlook 2014. International Energy Agency, Paris. 
IEA, 2015. World Energy Outlook 2015. IEA, Paris.

IGU, 2015. Wholesale Gas Price Survey - 2015 Edition. International Gas Union, Norway. Khalilpour, R., 2011. Selection of Liquefied Natural Gas (LNG) Contracts for Minimizing Procurement Cost. Industrial \& engineering chemistry research 50, 10298-10312.

Maxwell, D., Zhu, Z., 2011. Natural gas prices, LNG transport costs, and the dynamics of LNG imports. Energy Economics 33, 217-226.

Moryadee, S., Gabriel, S.A., Avetisyan, H.G., 2014. Investigating the potential effects of U.S. LNG exports on global natural gas markets. Energy Strategy Reviews 2, 273288.

Nexant, 2016. Wrold Gas Model. Avaiable at: http://thinking.nexant.com/program/world-gas-model [Accessed on.

Rogers, H., 2015. The Impact of Lower Gas and Oil Prices on Global Gas and LNG Markets. OIES, Oxford.

Rogers, H.V., Stern, J.P., 2014. Challenges to JCC Pricing in Asian LNG Markets. OIES, Oxford.

Rowley, A., 2014. Japan builds energy hub to tap US shale gas revolution, The Business Times. Singapore Press Holdings, Singapore.

Shanghai Daily, 2015. Exchange for piped gas and LNG opens. Avaiable at: http://www.shanghaidaily.com/business/energy/Exchange-for-piped-gas-andLNG-opens/shdaily.shtml [Accessed on: 2 Oct 2015].

Shi, X., Variam, H.M.P., 2015. China's Gas Market Liberalisation--The impact on ChinaAustralia gas trade, in: Song, L., Garnaut, R., Cai, F., Johnston, L. (Eds.), China's Domestic Transformation in a Global Context. ANU Press, Canberra, pp. 137-174.

Stern, J., 2014. International gas pricing in Europe and Asia: A crisis of fundamentals. Energy Policy 64, 43-48.

Stern, J.P. (Ed.), 2012. The Pricing of Internationally Traded Gas. Oxford University Press, Oxford.

Talus, K., 2011. Long-term natural gas contracts and antitrust law in the European Union and the United States. Journal of World Energy Law and Business 4, 260-315i.

The Japan Times, 2015. Editorials: Electricity and gas liberalization. Avaiable at: http://www.japantimes.co.jp/opinion/2015/07/05/editorials/electricity-and-gasliberalization/\#.Vx7hVN-qpBc [Accessed on: 2 Oct 2015].

Thomas, A., Grossman, J., Rohleder, T.R., Silver, E.A., 2000. A negotiation aid for "xedquantity contracts with stochastic demand and production. Int. J. Production Economics 66, 67-76.

Tong, X., Zheng, J., Fang, B., 2014. Strategic analysis on establishing a natural gas trading hub in China. Natural Gas Industry B 1, 210-220.

Tsukimori, O., 2015. Japan exchange says first LNG forward deal done. Reuters Avaiable at: $\quad$ http://uk.reuters.com/article/2015/07/31/japan-Ing-tradeidUKL3N10B30820150731 [Accessed on: 2 Oct 2015].

Wakamatsu, H., Aruga, K., 2013. The impact of the shale gas revolution on the U.S. and Japanese natural gas markets. Energy Policy 62, 1002-1009. 
World Bank, 2016. World Bank Commodities Price Forecast (January 2016). Avaiable at: http://www.worldbank.org/content/dam/Worldbank/GEP/GEP2015a/Price For ecast.pdf [Accessed on: 4 January 2016].

Yepes Rodríguez, R., 2008. Real option valuation of free destination in long-term liquefied natural gas supplies. Energy Economics 30, 1909-1932. 
Supplementary Material
Click here to download Supplementary Material: Appendix Assumptions.docx

Supplementary Material
Click here to download Supplementary Material: Appendix Assumptions.docx

X

(1) 
Table 1 Definition of regions

\begin{tabular}{|c|c|}
\hline Regions & Countries \\
\hline China & China \\
\hline Japan & Japan \\
\hline South Korea & South Korea \\
\hline $\begin{array}{l}\text { Chinese } \\
\text { Taipei }\end{array}$ & Chinese Taipei \\
\hline Russia & Russia \\
\hline $\begin{array}{l}\text { Asia-Pacific } \\
\text { exporters }\end{array}$ & Brunei Darussalam, Malaysia, Indonesia, Papua New Guinea, Australia \\
\hline Rest of Asia & $\begin{array}{l}\text { Bangladesh, Hong Kong, India, Mongolia, Nepal, Pakistan, Sri Lanka, } \\
\text { DPRK, Afghanistan, New Zealand, Singapore, Cambodia, Myanmar, } \\
\text { Philippines, Thailand, Vietnam }\end{array}$ \\
\hline Africa & $\begin{array}{l}\text { Algeria, Angola, Benin, Botswana, Cameroon, Congo, Cote d'Ivoire, } \\
\text { DR Congo, Egypt, Equatorial Guinea, Eritrea, Ethiopia, Gabon, Ghana, } \\
\text { Kenya, Libya, Morocco, Mozambique, Namibia, Nigeria, Senegal, } \\
\text { South Africa, Sudan, Togo, Tunisia, Tanzania, Zambia, Zimbabwe }\end{array}$ \\
\hline Europe & $\begin{array}{l}\text { Austria, Belgium, Czech Republic, Denmark, Finland, France, } \\
\text { Germany, Greece, Hungary, Iceland, Italy, Luxembourg, Netherlands, } \\
\text { Norway, Poland, Portugal, Slovak Republic, Spain, Sweden, } \\
\text { Switzerland, Turkey, United Kingdom, Albania, Bosnia and } \\
\text { Herzegovina, Bulgaria, Croatia, Cyprus, Macedonia (FYROM), } \\
\text { Romania, Serbia, Slovenia, Estonia, Latvia, Lithuania }\end{array}$ \\
\hline $\begin{array}{l}\text { Former Soviet } \\
\text { Union }\end{array}$ & $\begin{array}{l}\text { Armenia, Azerbaijan, Belarus, Georgia, Kazakhstan, Kyrgyzstan, } \\
\text { Moldova, Tajikistan, Turkmenistan, Ukraine, Uzbekistan }\end{array}$ \\
\hline Latin America & $\begin{array}{l}\text { Argentina, Bolivia, Brazil, Chile, Colombia, Cuba, Dominican } \\
\text { Republic, Peru, Trinidad and Tobago, Venezuela, Uruguay, Jamaica, } \\
\text { Puerto Rico, Panama }\end{array}$ \\
\hline Middle East & $\begin{array}{l}\text { Bahrain, Iraq, Iran, Israel, Jordan, Kuwait, Lebanon, Oman, Qatar, } \\
\text { Saudi Arabia, Syria, UAE, Yemen }\end{array}$ \\
\hline $\begin{array}{l}\text { North } \\
\text { America }\end{array}$ & Canada, Mexico, United States \\
\hline
\end{tabular}


Table 2 Summary of the Scenario Setting

\begin{tabular}{|l|c|c|}
\hline Scenarios & $\begin{array}{c}\text { Benchmark prices: } \\
\text { Oil (1); Shanghai (II); Tokyo (III) }\end{array}$ & $\begin{array}{c}\text { Destination Clause } \\
\text { (DS) }\end{array}$ \\
\hline Base & 1 all the time & Yes \\
\hline S1:Shanghai Hub & II from 2025 & Yes \\
\hline S2:Tokyo Hub & III from 2025 & No from 2020 \\
\hline S3a: Hub - No DS & As S1 & \multirow{2}{*}{ No from 2025 } \\
\hline S4a: Oil - No DS & As Base & \\
\hline S3b: Hub-No DS & As S1 & \\
\hline S4b: Oil - No DS & As Base & \\
\hline
\end{tabular}


Table 3: Overall cost of procurement (\% change vs base case) 2015-35 in Billions of USD (2012 price)

\begin{tabular}{|l|c|c|c|c|c|}
\hline & World & China & Japan & Korea & $\begin{array}{c}\text { Chinese } \\
\text { Taipei }\end{array}$ \\
\hline Base & 22294 & 6772 & 2263 & 1099 & 380 \\
\hline S1:Shanghai Hub & $\begin{array}{c}21770 \\
(-2.3 \%)\end{array}$ & $\begin{array}{c}6208 \\
(-8.3 \%)\end{array}$ & $\begin{array}{c}2097 \\
(-7.3 \%)\end{array}$ & $\begin{array}{c}995 \\
(-9 \%)\end{array}$ & $\begin{array}{c}356 \\
(-6.3 \%)\end{array}$ \\
\hline S2:Tokyo Hub & $\begin{array}{c}21635 \\
(-2.9 \%)\end{array}$ & $\begin{array}{c}6017 \\
(-11 \%)\end{array}$ & $\begin{array}{c}2065 \\
(-8.7 \%)\end{array}$ & $\begin{array}{c}977 \\
(-11 \%)\end{array}$ & $\begin{array}{c}348 \\
(-8.4 \%)\end{array}$ \\
\hline S3a: Hub - No DS & $\begin{array}{c}21360 \\
(-4.1 \%)\end{array}$ & $\begin{array}{c}5973 \\
(-12 \%)\end{array}$ & $\begin{array}{c}1913 \\
(-15 \%)\end{array}$ & $\begin{array}{c}844 \\
(-23 \%)\end{array}$ & $\begin{array}{c}340 \\
(-10 \%)\end{array}$ \\
\hline S4a: Oil - No DS & $\begin{array}{c}21547 \\
(-3.3 \%)\end{array}$ & $\begin{array}{c}6356 \\
(-6.1 \%)\end{array}$ & $\begin{array}{c}1915 \\
(-15 \%)\end{array}$ & $\begin{array}{c}845 \\
(-23 \%)\end{array}$ & $\begin{array}{c}340 \\
(-10 \%)\end{array}$ \\
\hline S3b: Hub-No DS & $\begin{array}{c}21870 \\
(-1.9 \%)\end{array}$ & $\begin{array}{c}6440 \\
(-4.9 \%)\end{array}$ & $\begin{array}{c}2075 \\
(-8.3 \%)\end{array}$ & $\begin{array}{c}958 \\
(-13 \%)\end{array}$ & $\begin{array}{c}362 \\
(-4.7 \%)\end{array}$ \\
\hline S4b: Oil - No DS & $\begin{array}{c}22055 \\
(-1.1 \%)\end{array}$ & $\begin{array}{c}6442 \\
(-4.8 \%)\end{array}$ & $\begin{array}{c}2075 \\
(-8.3 \%)\end{array}$ & $\begin{array}{c}960 \\
(-13 \%)\end{array}$ & $\begin{array}{c}362 \\
(-4.7 \%)\end{array}$ \\
\hline
\end{tabular}




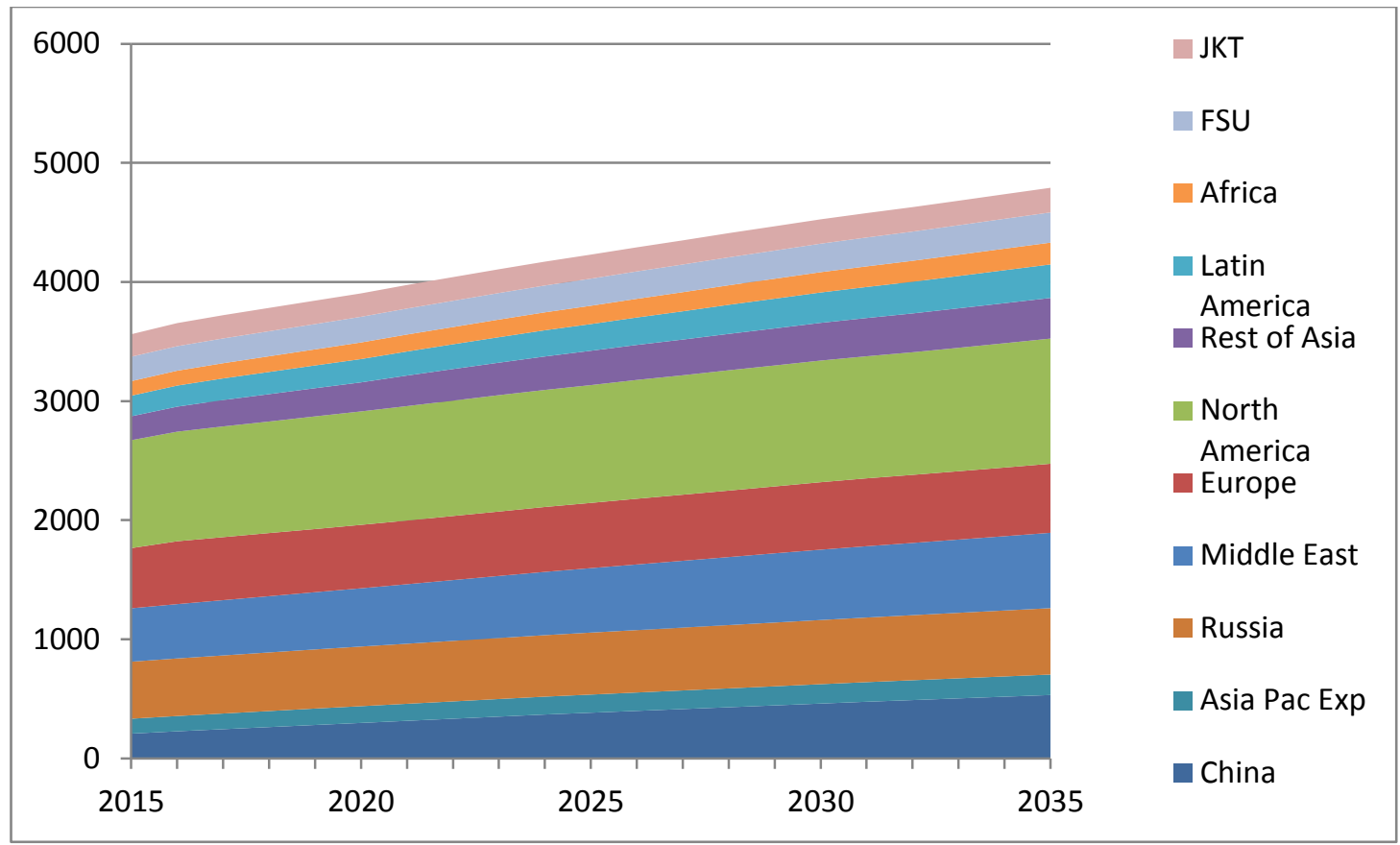

Figure 1 Gas Consumption Forecasts in bcm by Region (2006-2035)

Source: Model's projections 


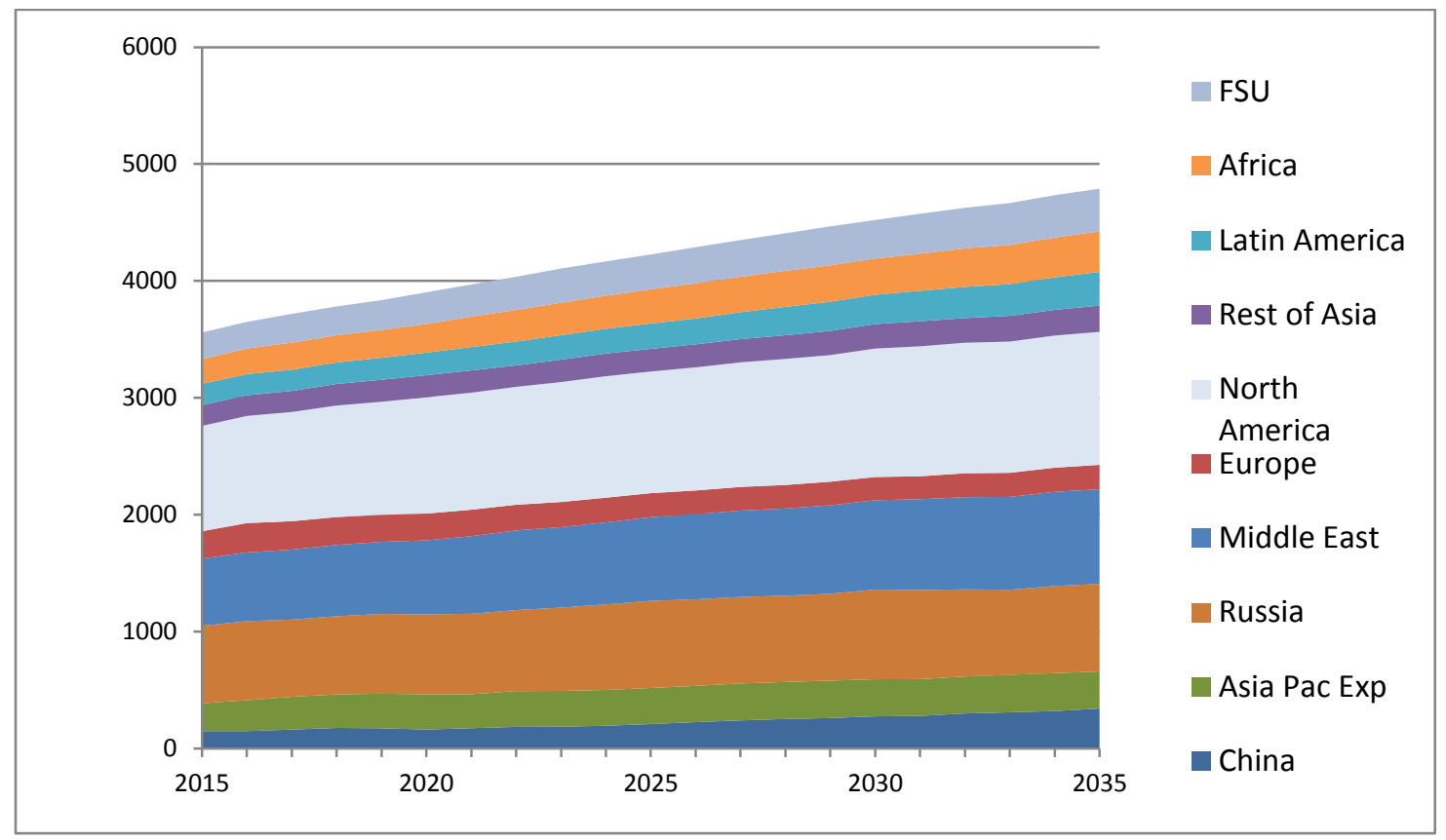

Figure 2 Gas Production Forecasts in bcm by Region (2015-2035)

Source: Model's projections 
Figure(s)

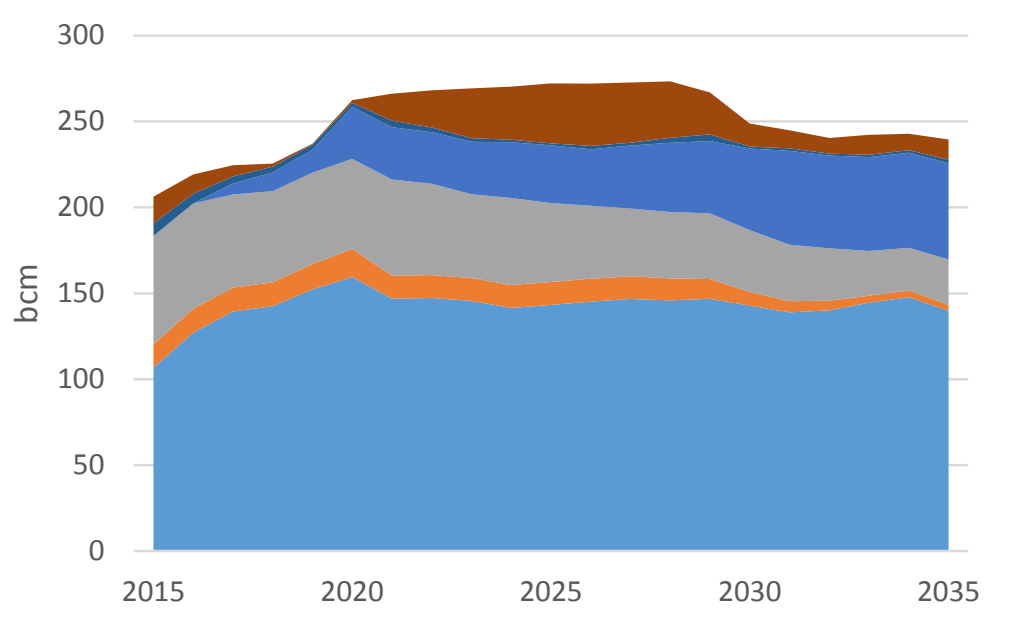

- Africa

- Latin America

Rest of Asia

north America

Europe

Middle East

Russia

Asia Pac Exp

Figure 3 LNG Flows to East Asia, 2015-2035

Source: Model's projections 


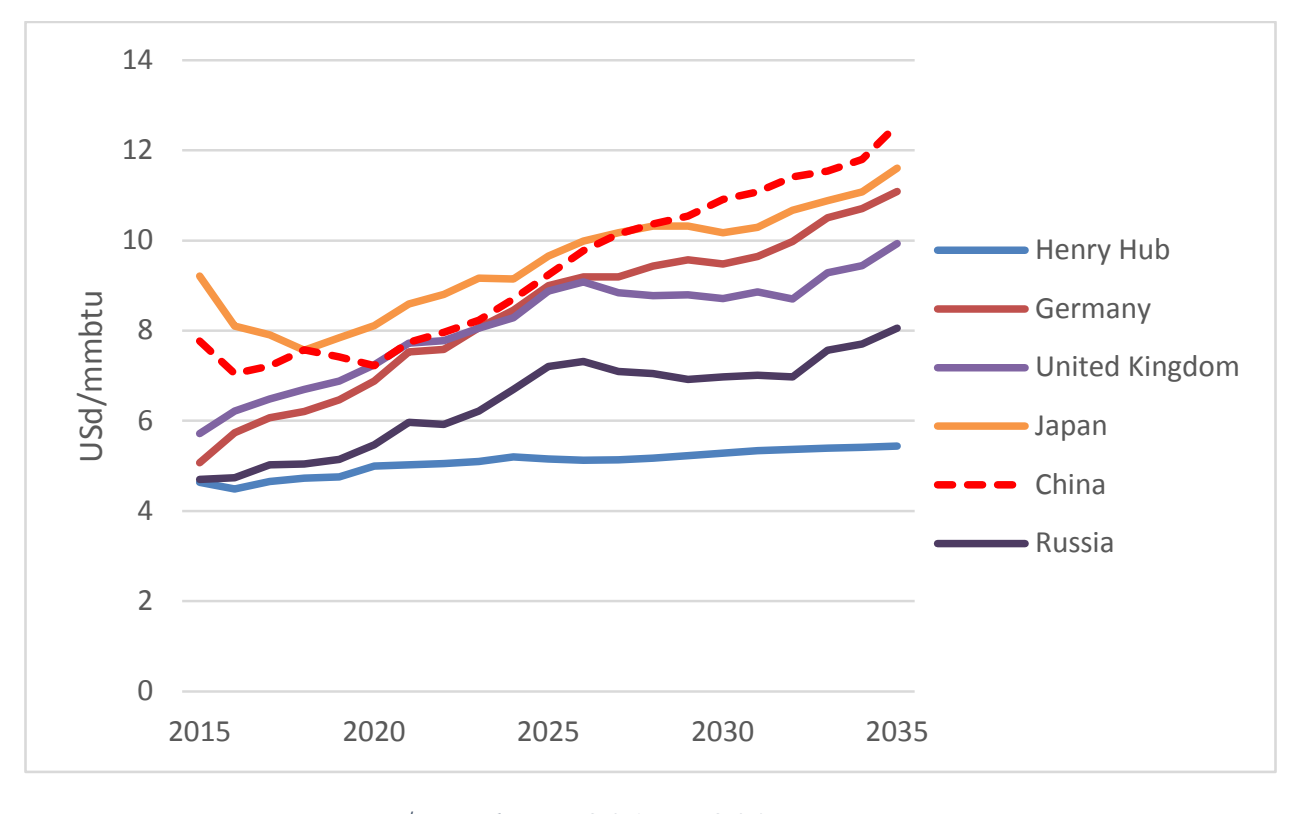

Figure 4 Gas Prices, Base Case $(\$ /$ mmbtu) $(2015-2035)$
Source: Model's projections

Figure 4 Gas Prices, Base Case (\$/mmbtu) $(2015$ - 2035)
Source: Model's projections

Figure(s) (s)

$$
\text { se }(\$ / m m b t u)(2015-2035
$$
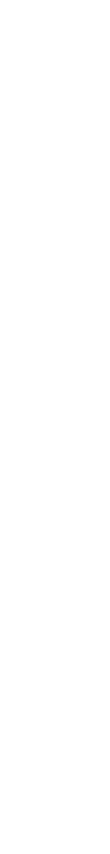


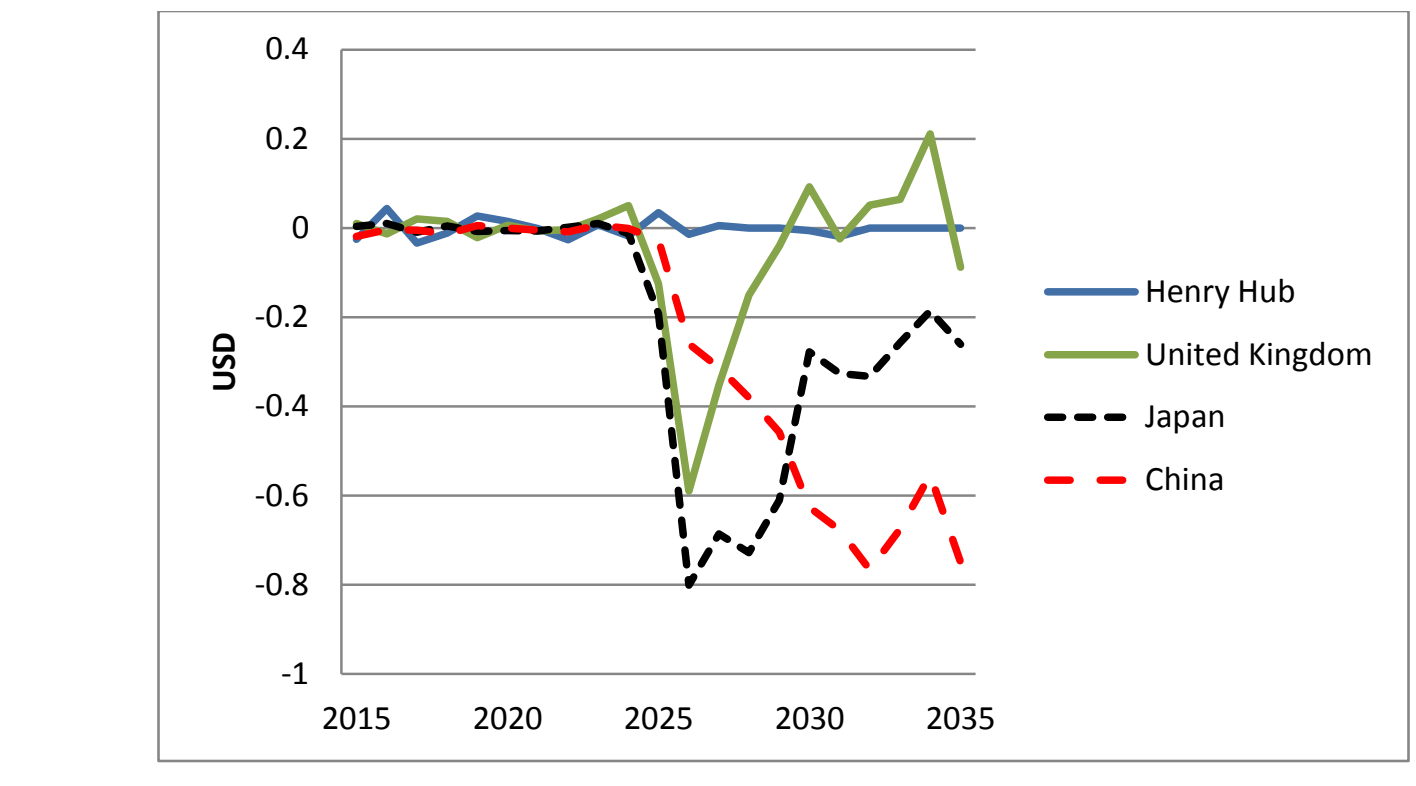

Figure 5: Spot Price: Shanghai Hub (S1) vs Base

Source: Model's projections

Source: Model's projections

\section{Figure(s)}

(1)

(

(

政

(

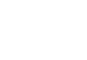

(1) 


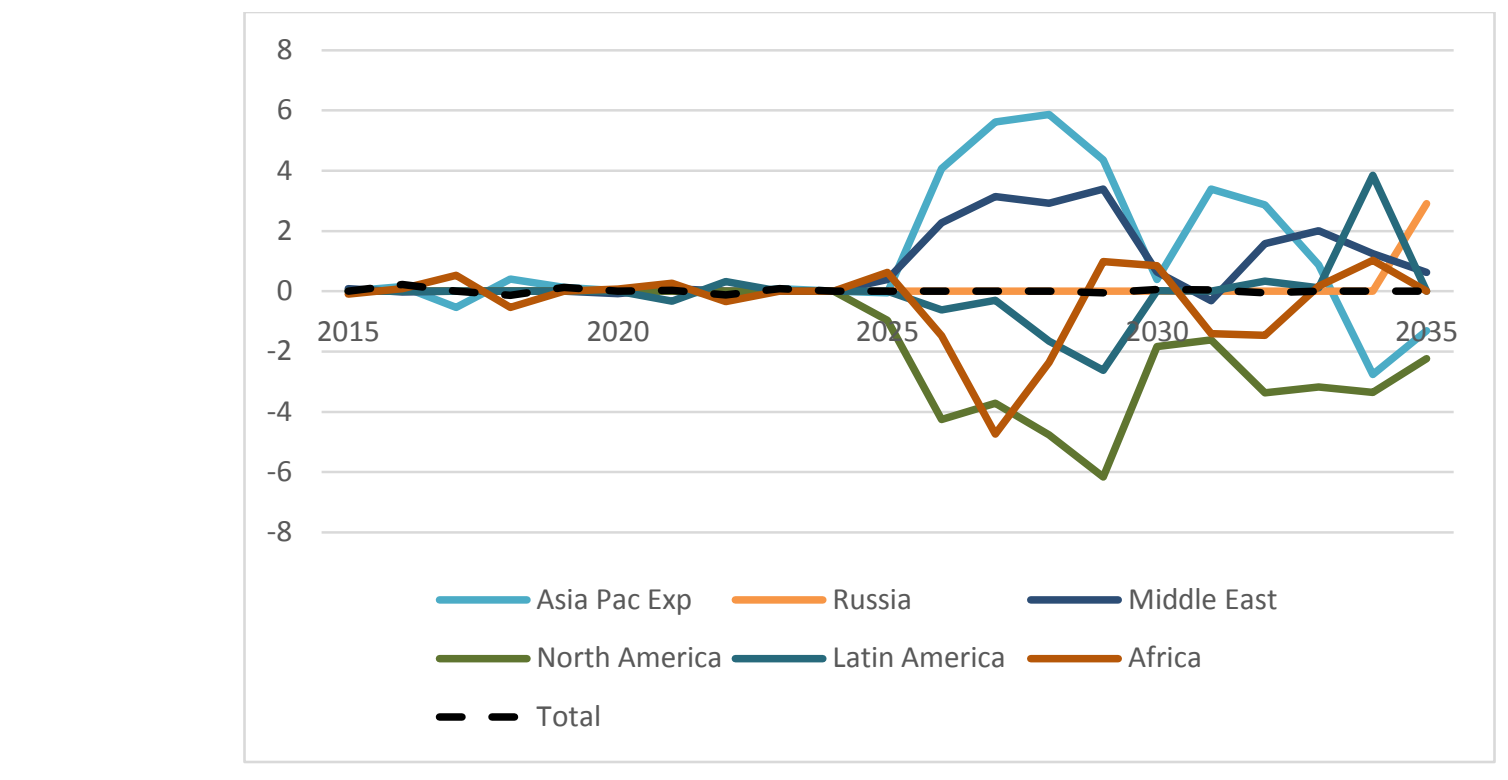

Figure 6 LNG Flows to Japan, Korea and Chinese Taipei (Shanghai Hub (S1) vs Base case)

Source: Model's projections Source: Model's projections

Source: Model's projections

Figure

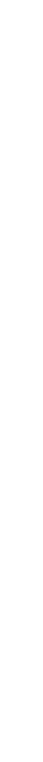
.

.

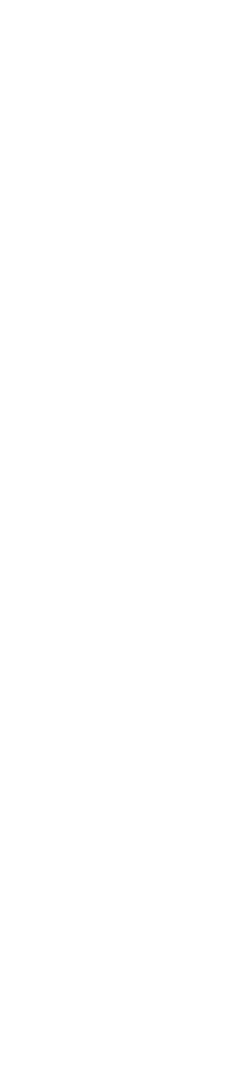

(1)

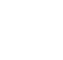

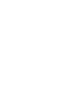




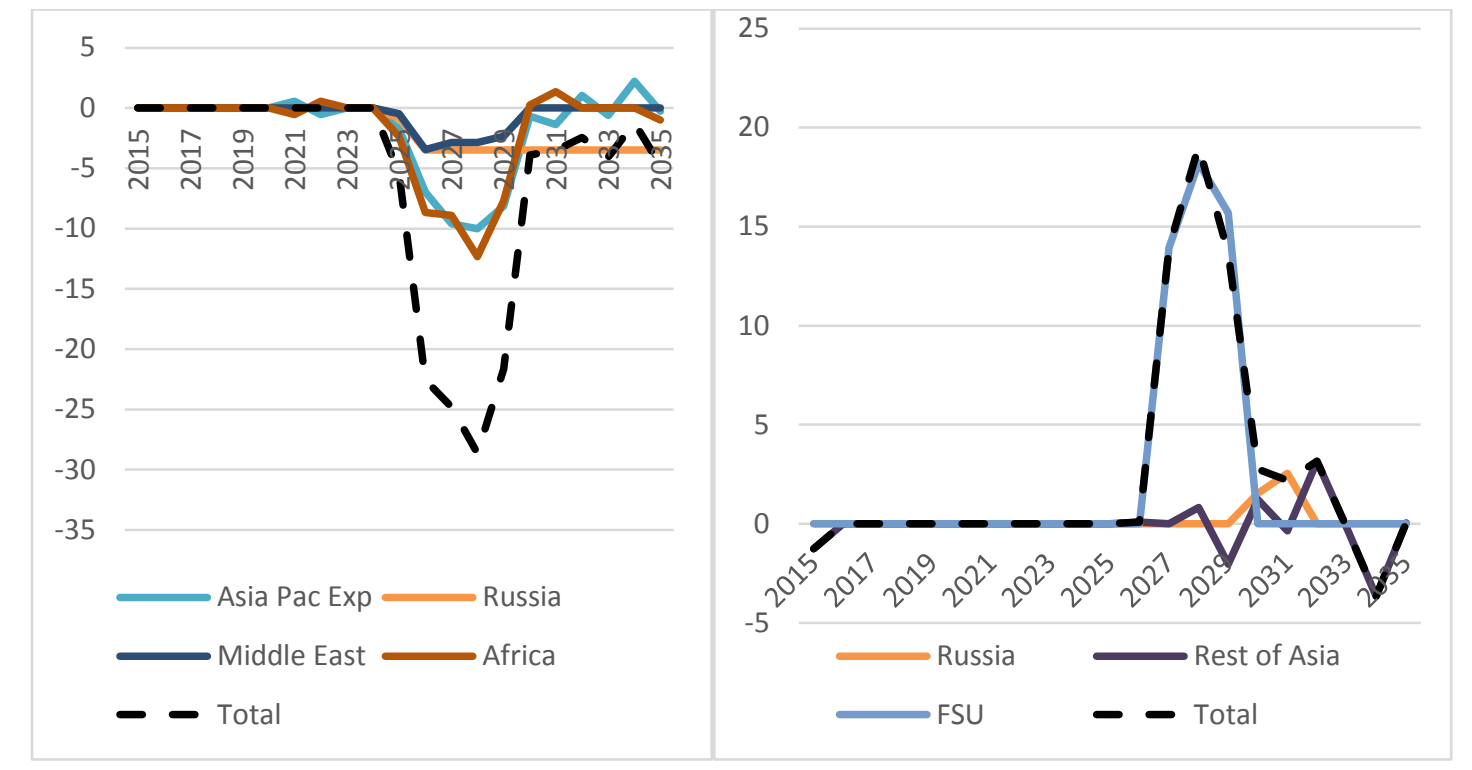

Figure 7 LNG and pipeline Flows to China in bcm (Shanghai Hub (S1) Vs Base scenario)

Source: Model's projections 


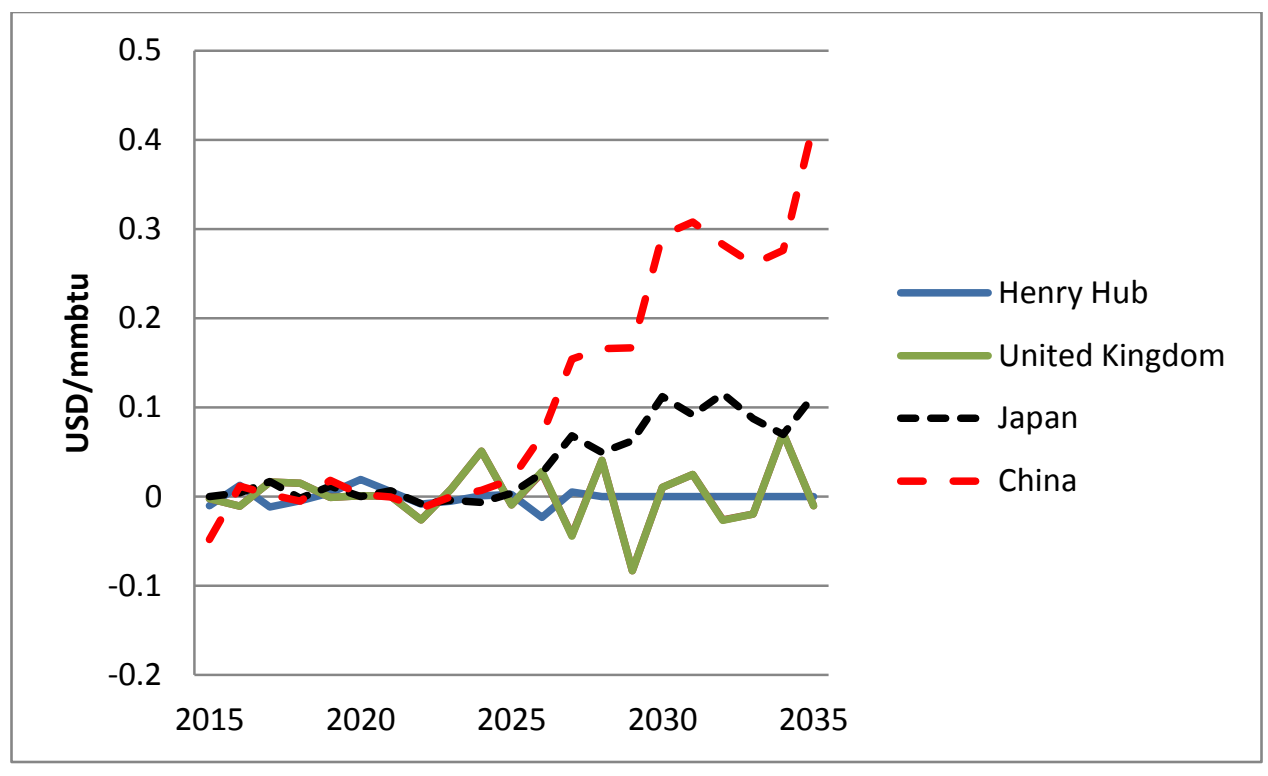

Figure 8: Spot price: Shanghai hub (S1) vs Tokyo hub (S2)

Source: Model's projections

Figure(s)

\title{
Figure(s)
}

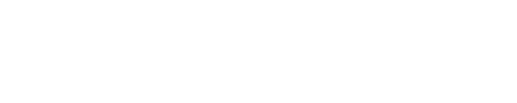

(1)

Source: Model's projections

$\sqrt{2}$

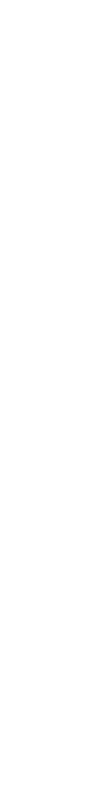

(

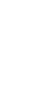

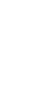

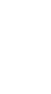

.

(
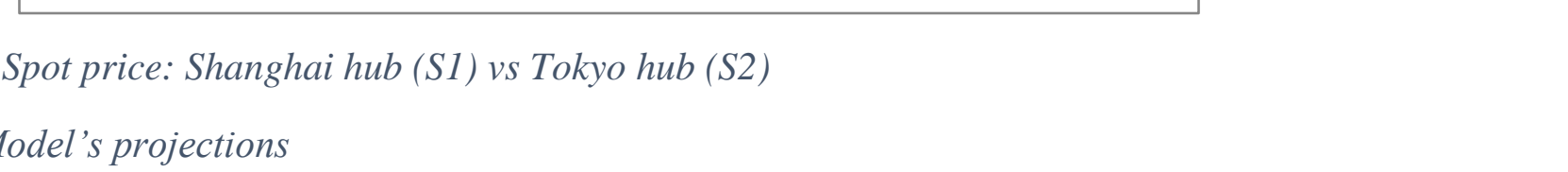

\begin{abstract}
.
\end{abstract} . 


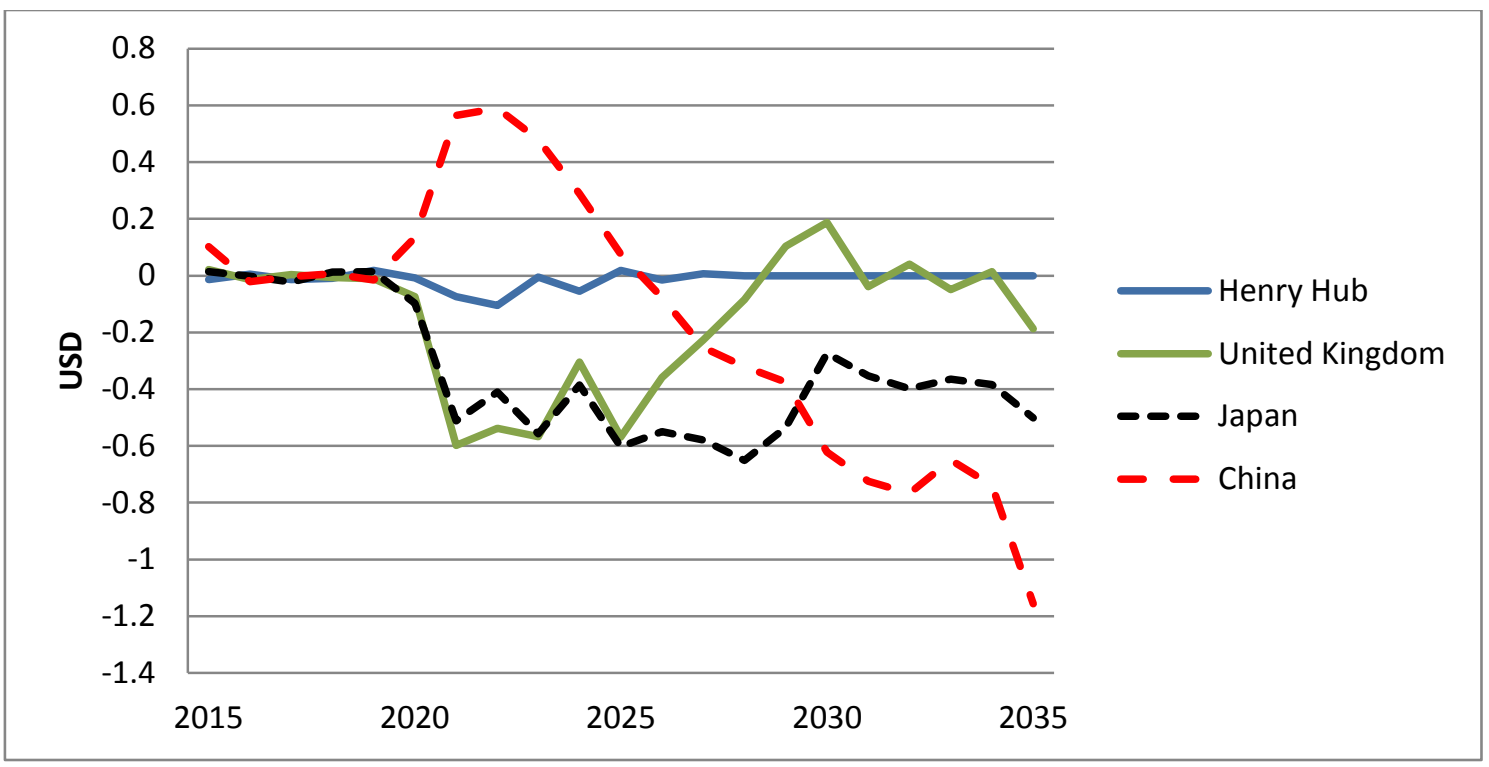

Figure 9: Spot price: Hub - No DS (3a) vs Base

Source: Model's projections 
Figure(s)

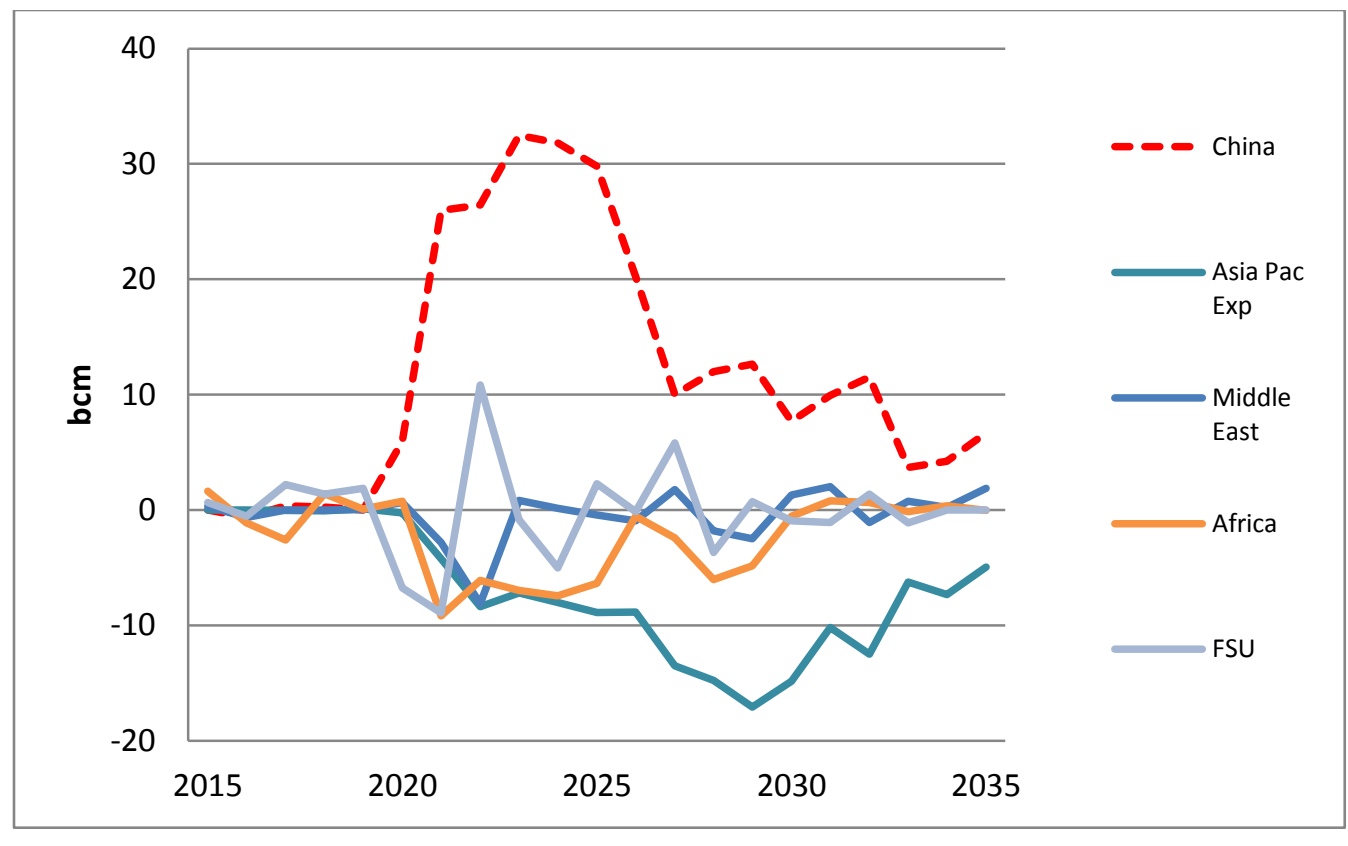

Figure 10 Production: 'Hub-No DS' (3a) vs Base

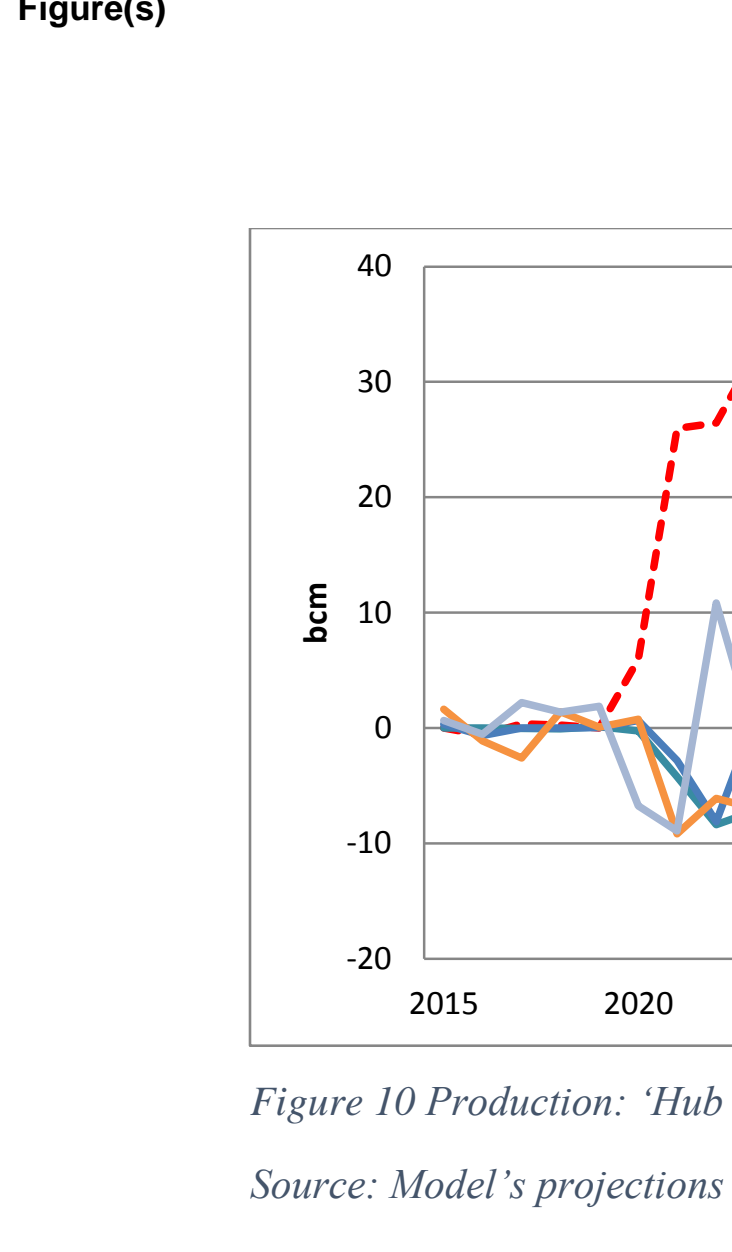

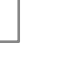

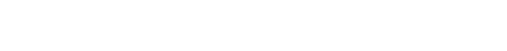

$2025 \quad 2030$

$2025 \quad 2030 \quad 2035$
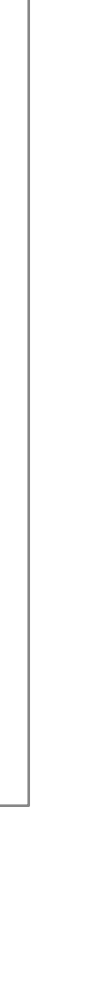

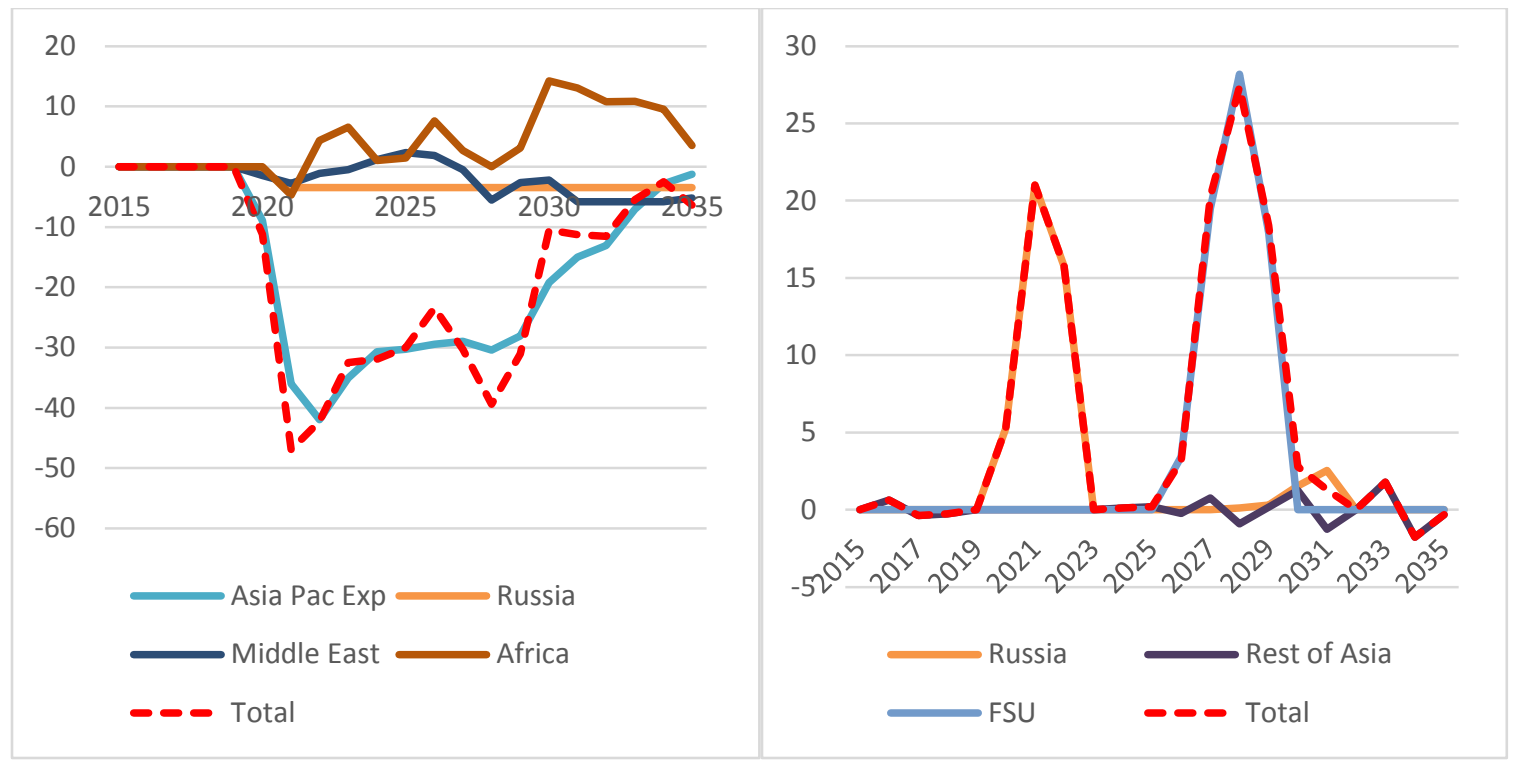

Figure 11 LNG and pipeline flows to China: Hub No DS (3a) vs Base

Source: Model's projections 


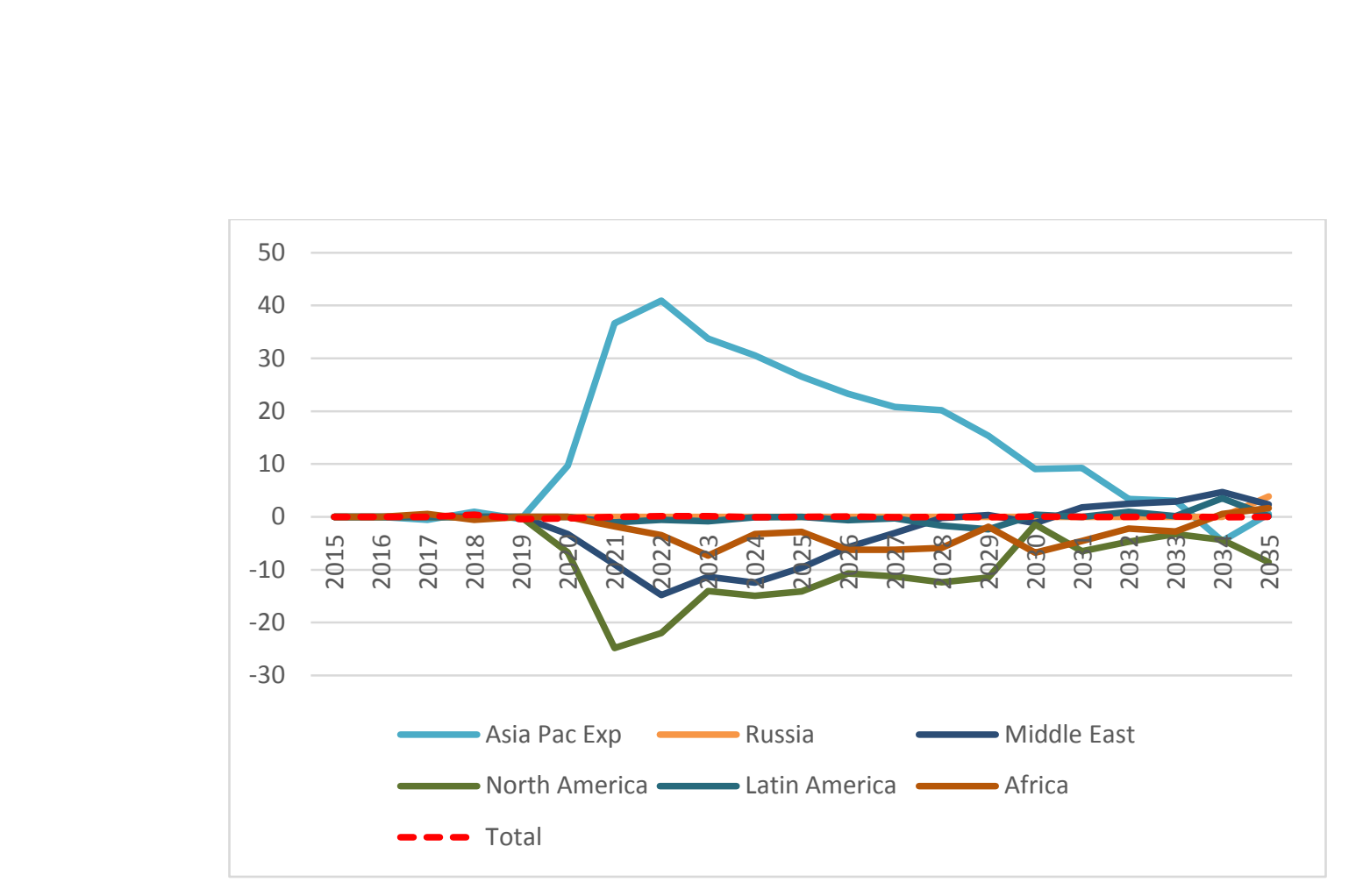

Figure 12 LNG Exports to Japan, Korea and Chinese Teipei (S3a vs Base) in bcm

Source: Model's projections

Source: Model's projections

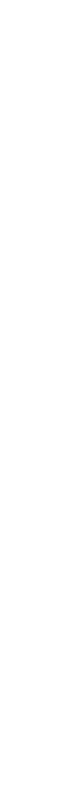

Figure(s) (a) 


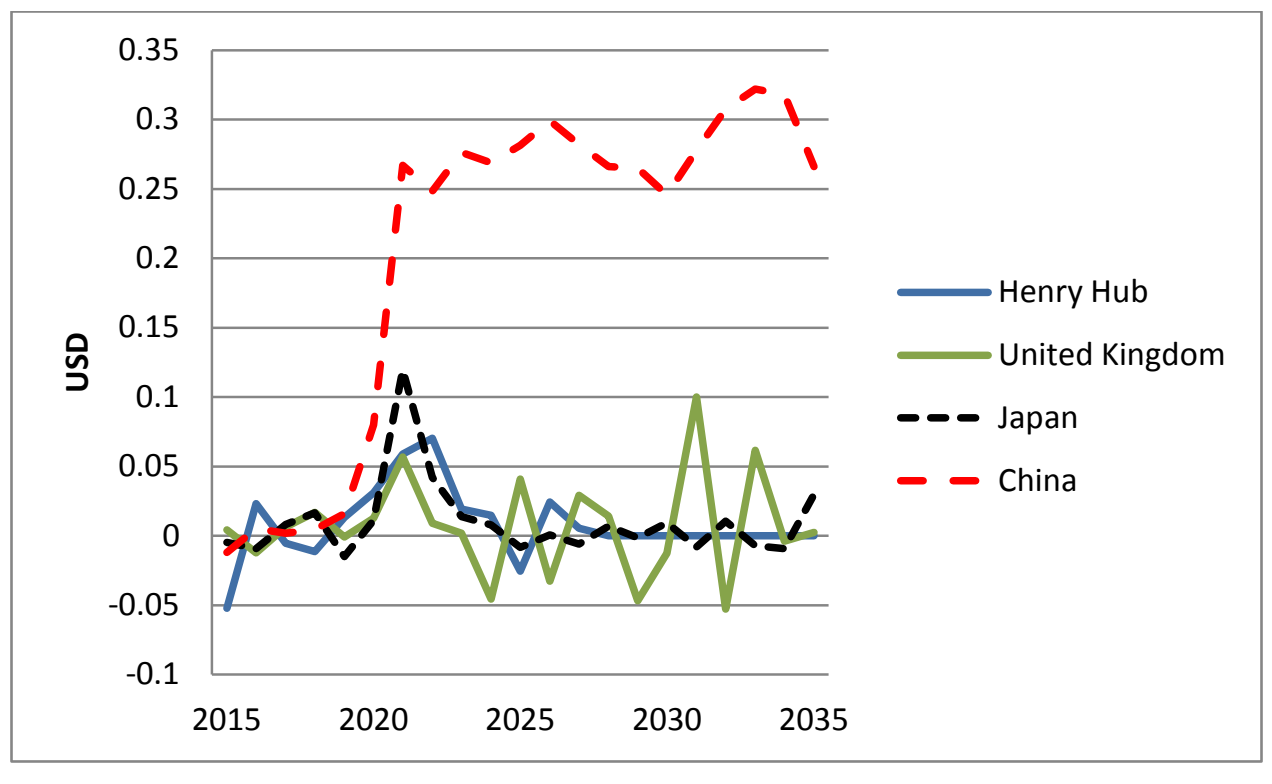

Figure13: Spot price: Oil no DS (3a) vs Spot No DS (4a)

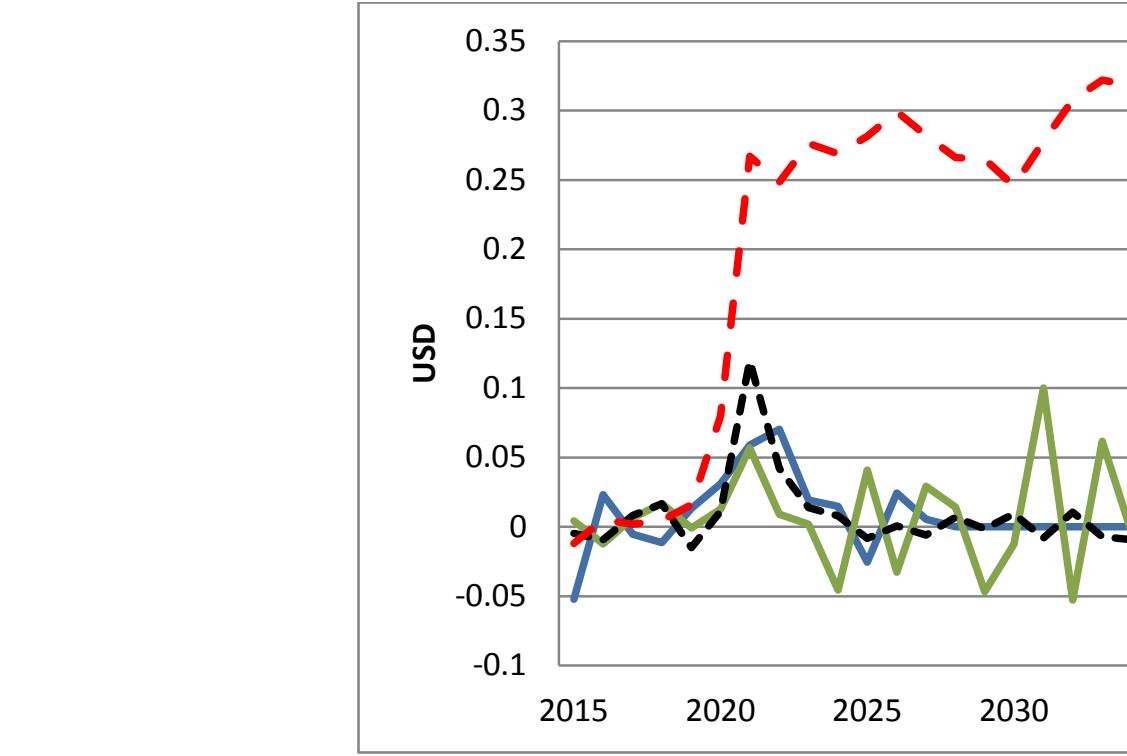

( $\sqrt{2}$

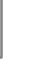

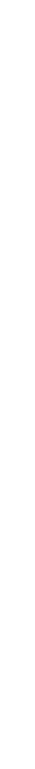

(2)

(1)

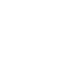

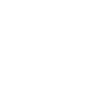

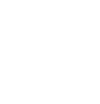

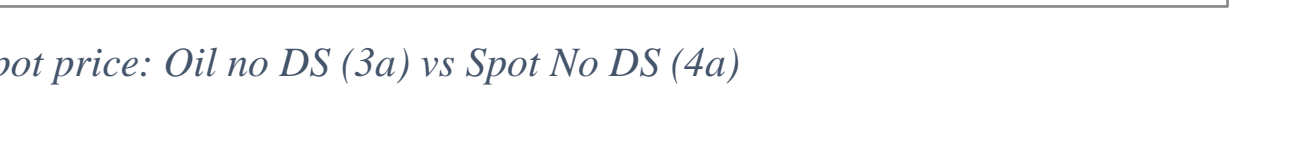

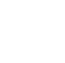

